Rev. Hist., $\mathrm{N}^{\circ} 27$, vol. 2, Julio-Diciembre 2020: 37-69

ISSN 0717-8832

https://doi.org/10.29393/RH27-11CVMG10011

\title{
¿Colonizando el valle central y el borde costero? Dos historias de inmigración y de adaptación ambiental en el antiguo departamento de Imperial, región de La Araucanía (1866-1920).
}

\author{
Colonizing the central valley and the coastal border? The case of the Imperial \\ department, in the region of Araucania (Chile) and the environmental adaptation of \\ settlers, from 1866 to 1920.
}

Matías González Marilicán: ORCID: https://orcid.org/0000-0003-0393-8021*

\section{Resumen}

Los estudios migratorios de La Araucanía no han considerado, suficientemente, al medio ambiente en sus explicaciones. A través de una revisión de documentación histórica, se analizó la influencia del medio ambiente en las inmigraciones vividas en el departamento de Imperial, región de La Araucanía, a finales del siglo XIX e inicios del siglo XX. Los resultados sugieren que hubo dos casos de inmigración en el departamento. En el borde costero, el medio ambiente se impuso, en general, a los colonos; mientras que, en la depresión intermedia, los habitantes parecieron adaptarse, de mejor forma, al entorno natural.

Palabras claves: Historia Ambiental, Migraciones, Chile, Araucanía.

\section{Abstract}

The migration studies of the region of Araucanía have not sufficiently considered the environment in their accounts. Through a review of historical documents, the influence of the environment on immigration in the imperial department of Araucanía, in the late XIX century and the early XX century, has been studied. The results suggest that there were two cases of immigration in the region. On the coastal border, the environment imposed itself, generally, on the settlers; while, in the intermediate depression, the inhabitants seemed to adapt themselves, in the best way, to their natural environment.

Key Words: Environmental History, Migration, Chile, Araucania.

Recibido: enero 2020

Aceptado: junio 2020

\footnotetext{
* Docente Carrera de Pedagogía en Historia, Geografía y Ciencias Sociales, Facultad de Educación, Departamento de Educación Media, Universidad Católica de Temuco. Correo electrónico: matias.gonzalez@educa.uct.cl. El autor quiere agradecer a los profesionales y funcionarios del Archivo Histórico Nacional, Biblioteca Nacional y Archivo Regional de La Araucanía por facilitar el acceso a la información. Asimismo, se agradece al historiador Hernán González Quitulef por revisar el primer manuscrito de esta investigación, así como también a los dos revisores anónimos cuyos comentarios fueron valiosos para producir la versión final de este estudio.
} 


\section{Introducción}

La colonización de La Araucanía, por parte de chilenos y de extranjeros, en la segunda mitad del siglo XIX, se realizó, en general, a través de tres estrategias ${ }^{1}$. La primera consistía en habilitar tierras por medio de la llamada comisión radicadora. Esta debía situar a las comunidades mapuche en nuevos terrenos con tal de dejar espacio para la llegada de nuevos pobladores. La segunda estrategia trataba de rematar tierras fiscales, previamente hijueladas. Aquí los topógrafos e ingenieros cumplieron un rol fundamental al dividir los terrenos, muchos de ellos boscosos, según dimensiones establecidas por el Gobierno. Finalmente, se entregaron tierras a colonos extranjeros, que, enganchados por agentes de colonización radicados en Europa, se encargaron de traerlos previa firma de contrato con el Gobierno chileno. A partir de 1890 comenzó la venida de colonos por cuenta personal. El Gobierno había permitido esta posibilidad al haber satisfecho su interés de colonización en décadas anteriores. En todo caso, se generaron contratos con personas jurídicas o naturales que se ofrecían a traer colonos extranjeros a La Araucanía, a cambio de ciertas franquicias otorgadas por el Estado. De aquí el surgimiento de empresas colonizadoras, como "Nueva Italia", "Colonia del Budi" o "Sociedad Lanín". Si bien, entre los colonos extranjeros se podían encontrar diversas nacionalidades europeas, los números más altos provinieron de Suiza y de Alemania. Los lugares de asentamiento fueron variados, aunque pareciera ser que la provincia de Malleco alojó a la mayoría de los colonos europeos².

La inmigración de colonos fue vista como un medio fundamental para construir la nación que se deseaba. Con colonos se pondrían en producción las tierras feraces que se anexionarían al país con la ocupación del territorio mapuche. En 1877, el teniente Ambrosio Letelier visitó la región para revisar el estado de avance de los fuertes construidos por el ejército, y escribió en su informe: "Necesitamos llevar población a los campos desiertos, llevar industria, comercio, trabajo"3. Una opinión similar tuvo el capitán de fragata Federico Chaigneau cuando en 1893 visitó Carahue. Según él: “Una vez que todas estas tierras estén en poder de gente laboriosa, esta comarca se convertirá en un centro productor de primera clase para los cereales" 4 . Además, se pensaba que con los colonos europeos, se contagiaría de civilización al resto del campesinado chileno e indígena, volviéndolo más disciplinado y productivo ${ }^{5}$.

\footnotetext{
${ }^{1}$ Ferrando, Ricardo. 2012. Y así nació La Frontera...Conquista, guerra, ocupación, pacificación, 1550-1900, Temuco, Universidad Católica de Temuco, pp. 599-630.

${ }^{2}$ Ibíd., pp. 599-630.

3 Villalobos, Sergio. 2013. Incorporación de La Araucanía. Relatos Militares, 1822-1883, Santiago, Catalonia, p. 201.

${ }^{4}$ Chaigneau, Federico. 1896. "Viaje al río Imperial en noviembre de 1893 por el capitán de fragata Don J. Federico Chaigneau", en Anuario Hidrográfico de la Marina de Chile, 20, Santiago, p. 51

${ }^{5}$ Zavala, José. 2018. "En busca del ciudadano ideal: fundamentos discursivos de la colonización inmigratoria de La Araucanía durante el siglo XIX", en Mora, Héctor; y Mario Samaniego (editores) El pueblo mapuche en la pluma de los araucanistas. Seis estudios sobre construcción de la alteridad,, Santiago, Ocholibros, pp. 167-185.
} 
La venida de colonos a La Araucanía ha llamado la atención de los estudiosos por diferentes motivos. Fue un proceso que implicó maltratos e injusticias al colono, tanto nacional como extranjero-por ejemplo, por parte del Estado o de las empresas colonizadoras ${ }^{6}$; fue un acontecimiento que reforzó la mirada colonialista del Estado chileno para con el pueblo mapuche $^{7}$; y fue un evento que no solo implicó la venida de agricultores o industriales, sino que también de bandoleros o delincuentes ${ }^{8}$. Sin embargo, el problema con estos enfoques es que parecen centrarse en aspectos fundamentalmente humanos ${ }^{9}$. Se analizan las leyes de inmigración, las políticas gubernamentales de colonización, los robos y asesinatos, el origen profesional de los colonos y su relación con el pueblo mapuche. Sin embargo, en ningún momento se habla con detalle de otro factor no menos importante en los procesos migratorios: el medio ambiente. En efecto, si es que aparece, lo hace como mero escenario de los acontecimientos y como factor que pareciera solo decidir la suerte de los colonos en los primeros años de su llegada, para luego desaparecer por la preminencia de eventos humanos como los nombrados más arriba. Como bien lo ha señalado el historiador Donald Hughes, la historia que falle en integrar al medio ambiente en sus explicaciones, será un relato parcial e incompleto, pues el medio ambiente le puede añadir base y perspectiva a temáticas tradicionalmente abordadas por los historiadores, como la economía, la diplomacia, la guerra y la filosofía, entre otras ${ }^{10}$. Es cierto que se han hecho esfuerzos en la historiografía regional para corregir este sesgo ${ }^{11}$, sin embargo, es algo que se debe seguir haciendo, sobre todo cuando los actuales estudios de inmigración en Chile también omiten al medio ambiente en sus explicaciones ${ }^{12}$. Por lo tanto, una forma de complementar la historiografía chilena y de La Araucanía, es analizando la influencia que el medio ambiente tuvo en los procesos inmigratorios vividos en el departamento de Imperial, región de La Araucanía, entre los años de 1866 y 1920.

\footnotetext{
${ }^{6}$ Villalba, Álvaro. 2013. "Conflicto político y social en la Araucanía a principios del siglo XX, en el proceso de colonización extranjera con españoles canarios en la zona del Budi", en Carlos Zúñiga (compilador), Fragmentos de Historia Regional. La Araucanía en el siglo XX, Temuco, ediciones Universidad de la Frontera, pp. 122-157.

7 Zavala, José. 2018. "En busca del ciudadano ideal", pp. 167-185.

8 Pinto, Jorge. 2011. Araucanía, siglos XIX y XX, Economía, Migraciones y Marginalidad, Ediciones Universidad de la Frontera, Temuco, passim.

${ }^{9}$ Worster, Donald. 1988. "Appendix: Doing Environmental History", en The Ends of the Earth. Perspectives on modern environmental history, Donald Worster (editor), Cambridge, Cambridge University Press, pp. 289-307.

${ }^{10}$ Hughes. 2016. What is Environmental History?, Cambridge, Polity Press, p. 18.

11 Pinto, Jorge y Mathias Órdenes. 2015. Chile, una economía regional en el siglo XX. La Araucanía 1900-1960, Temuco, Ediciones Universidad de La Frontera, pp. 151-207; Miller K., Thomas. 2014. La Frontera. Forests and Ecological Conflict in Chile's Frontier Territory, Durham, Duke University Press.

12 Tijoux, María E. 2016. Racismo en Chile. La piel como marca de la inmigración, Santiago, Editorial Universitaria, passim; Aninat, Isabel; y Rodrigo Vergara. 2019. Inmigración en Chile. Una Mirada multidimensional, Santiago, Fondo de Cultura Económica, passim; Rojas, Nicolás; y José Vicuña. 2019. Migración en Chile. Evidencia y mitos de una nueva realidad, Santiago de Chile, LOM editores, passim.
} 


\section{Metodología}

\section{Diseño de investigación}

Se ocupó un diseño de investigación de tipo intensivo, es decir, centrado en un caso en particular. Este enfoque pretende describir a un objeto de estudio con el máximo de detalles posibles $^{13}$. Asimismo, se empleó metodología histórica-ambiental y técnica mixta para lograr el objetivo de investigación propuesto ${ }^{14}$.

La historia ambiental se preocupa de estudiar la relación ser humano-medio ambiente a lo largo del tiempo y, para hacerlo, lo hace a través de tres líneas de investigación interrelacionadas, pero que no necesariamente deben estar siempre presentes, a saber: la influencia del medio ambiente sobre la vida del ser humano, el impacto de este sobre el mundo natural y las ideas que el ser humano ha tenido respecto al medio ambiente ${ }^{15}$. El siguiente trabajo se centra preferentemente en la primera línea investigativa de la historia ambiental, es decir, la que estudia la influencia del medio ambiente en la historia humana, a través del clima, de enfermedades, de inundaciones, de terremotos, etc ${ }^{16}$. En este caso se considerarán, fundamentalmente, la influencia del clima, de los ríos y de los bosques.

La historia ambiental surgió en los Estados Unidos de América, en la década de 1970, en medio del malestar social generado por la guerra nuclear y por el impacto del ser humano en el medio ambiente natura ${ }^{17}$. En la década de 1990 ya se podía encontrar a la subdisciplina siendo practicada por historiadores en Europa, $\mathrm{y}$, sobre todo, a partir del siglo XXI, por investigadores en Asia, Oceanía, África y América Latina ${ }^{18}$. Si bien, esta última región debe avanzar más en lo que es la historia ambienta ${ }^{19}$ - especialmente en países como Chile, Bolivia, Perú y Ecuador $^{20}$-, parece haber consenso de que en la actualidad el panorama

\footnotetext{
${ }^{13}$ Clifford, Nick; French, Shaun; y Gill Valentine. 2010. "Getting Started in Geographical Research: how this book can help", en Clifford, Nicholas; French, Shaun y Gill Valentine (editores), Key Methods in Geography, Los Angeles, Sage publications, pp. 3-16.

${ }^{14}$ Hughes, Donald. 2016. What is Environmental History?, pp. 122-129.

15 Ibíd., pp. 4-10.

16 Ibíd., p. 5.

${ }^{17}$ Ibíd., pp. 37-39.

${ }^{18}$ Ibíd., pp. 52-83.

${ }^{19}$ Se ha señalado que los estudios de historia ambiental aún son fragmentados en la región y que se requieren mayores esfuerzos, en conjunto, para impulsar a la subdisciplina. Véase para esto: Soluri, John; Leal, Claudia; Pádua, José. 2019. "Introducción. Lo 'latinoamericano' en la historia ambiental de América Latina", en Leal, Claudia; Soluri, John; Pádua, José (editores), Un pasado vivo. Dos siglos de historia ambiental latinoamericana, México D.F., Fondo de Cultura Económica, pp. 11-32.

${ }^{20}$ Quien escribe tuvo la oportunidad de participar en cada una de las jornadas del Tercer Congreso Mundial de Historia Ambiental, llevado a cabo en Florianópolis, Brasil, desde el 22 al 26 de julio, en el año 2019. Este fue el primer congreso de este tipo celebrado en América Latina. Aquí el autor fue testigo de la baja participación de Bolivia, de Perú y de Ecuador, entre otros países, en las exposiciones y en el público asistente. Todo indica que Brasil y Colombia poseen un alto interés por la materia, pues un gran número de participantes provenían de estos países.
} 
latinoamericano de historia ambiental se encuentra más sólido que nunca ${ }^{21}$. Para John Soluri, Claudia Leal y José Augusto Pádua ya se podría distinguir, inclusive, una suerte de identidad latinoamericana en la forma de escribir la historia ambiental. En efecto, según los historiadores, las herencias del colonialismo ibérico, la formación y persistencia de los estados nacionales, los intercambios interoceánicos y la tropicalidad han constituido los principales ejes de las historias ambientales latinoamericanas en el último tiempo ${ }^{22}$. Con todo, dicen los mismos historiadores, "son muchos los tipos de relaciones y sistemas socioecológicos en América Latina cuyas historias aún no han sido examinadas en detalle. Por ejemplo, todavía son escasos los estudios sobre ambientes acuáticos [...] sabanas [...] desiertos y [...] zonas secas". Para ellos, estos ecosistemas merecen tanto atención como los bosques ${ }^{23}$.

El presente trabajo busca aportar a la historia ambiental chilena no desde la exclusividad de los bosques, sino desde las migraciones y su relación con el medio ambiente en general. En este sentido, este estudio puede ser inscrito en dos de los cuatro ejes temáticos señalados por Soluri, Leal y Pádua para América Latina, a saber: los estados nacionales y su afán por ejercer control territorial y por explotar los recursos naturales existentes en él a lo largo de los siglos XIX y XX; $\mathrm{y}$, los intercambios ecológicos derivados de las migraciones y contactos interoceánicos.

De hecho, quienes lideran la actual Sociedad Latinoamericana y Caribeña de Historia Ambiental son principalmente colombianos y brasileños. En el caso chileno, no existe una comunidad clara de historia ambiental y tampoco ha habido trabajos a modo de síntesis de lo que ha sido la historia del país en relación a la naturaleza. Sin embargo, todo indica que cada vez más se van integrando más investigadores a esta área de estudio. Quizás lo que mejor evidencia esta evolución fue la alta convocatoria que tuvieron las mesas de historia ambiental en las XXIII Jornadas de Historia de Chile, organizadas por la Universidad de Chile, en Santiago, en los días 21, 22 y 23 de octubre, del año 2019. Por primera vez, decían los organizadores, se instalaron mesas de historia ambiental en un evento de este tipo.

${ }^{21}$ En la primera década del siglo XXI, los historiadores John McNeill y Stefania Gallini hacían un llamado a explotar aún más la historia ambiental en América Latina, pues existían diversas fuentes y temas que aguardaban a los investigadores, como la transformación de los ríos por el ser humano, el impacto de la minería en la litosfera y la transformación del paisaje producto de la inserción de especies foráneas. Según McNeill, al parecer, ha sido el conservadurismo historiográfico de la región lo que ha atentado con el avance de la historia ambiental. Este panorama, visto en retrospectiva, ya no parece tan alicaído como antes, ya que, como se verá, se podría identificar una cierta identidad latinoamericana en la producción de historias ambientales. Para todo esto, véase: McNeill, John. 2005. "Naturaleza y cultura de la historia ambiental”, en Nómadas no 22, Bogotá, pp. 12-25; Gallini, Stefania. 2009. "Historia, ambiental, política: el camino de la historia ambiental en América Latina", en Nómadas, no 30, Bogotá, pp. 92-102.

22 Soluri, John; Leal, Claudia; Pádua, José. 2019. “Introducción. Lo 'latinoamericano' en la historia ambiental de América Latina", pp. 11-32.

${ }^{23}$ Los bosques han sido los ecosistemas preferidos por los historiadores ambientales de América Latina y con razón, dicen Soluri, Leal y Pádua, pues han manifestado un abrupto retroceso producto de la actividad humana a lo largo de la historia. Soluri, John; Leal, Claudia; Pádua, José. 2019. “Introducción. Lo 'latinoamericano' en la historia ambiental de América Latina", pp. 11-32. En Chile, se podría decir que las historias ambientales más representativas del país son acerca de bosques. Véase por ejemplo: Camus G., Pablo. 2006. Ambiente, Bosques y Gestión Forestal en Chile. 1541-2005, Santiago, LOM ediciones; Miller K., Thomas. 2014. La Frontera. Forests and Ecological Conflict in Chile's Frontier Territory, Durham, Duke University Press; Otero D., Luis. 2006. La huella del fuego. Historia de los bosques nativos. Poblamiento y cambios en el paisaje del sur de Chile, Santiago, Pehuén editores. 


\section{Área de estudio}

El área de estudio fue definida en base a criterios geográficos y administrativos (Figura 1). Los orígenes del departamento de Imperial, en la región de La Araucanía, se pueden remontar hacia finales de la década de 1860, cuando el Estado ocupa el litoral de la región con las fundaciones de los fuertes de Queule y Toltén. Gobernada en un principio por militares, desde 1887 a 1960 el departamento pasó a estar encabezada por una autoridad civil llamada gobernador ${ }^{24}$. Este era un territorio que limitaba con las provincias de Arauco y Malleco por el Norte, con el departamento de Temuco por el oriente; la provincia de Valdivia por el Sur y el océano Pacífico por el Oeste. Inserto en la provincia de Cautín, el departamento de Imperial se encontraba dividido en cuatro subdelegaciones, a saber: las de Nueva Imperial, Bajo Imperial o Puerto Saavedra, Carahue, Toltén y Boroa ${ }^{25}$.

Geográficamente, el departamento de Imperial era un territorio extenso y con diversos ecosistemas. Poseía un litoral cercano a los $193 \mathrm{~km}$ de longitud y un ancho que, desde el Pacífico hacia el interior, podía llegar a los $100 \mathrm{~km}$. Abarcó tres estructuras morfológicas distintivas del territorio chileno, a saber: la franja litoral, la cordillera de la costa y el valle central o depresión intermedia. La franja litoral se extiende a lo largo de todo el borde costero y con alturas que oscilan entre los 0 a $200 \mathrm{msnm}$. Esta se encuentra limitada al Oeste por el océano Pacífico y, al Este, por la cordillera de la costa. Desde el río Imperial hacia el Norte, la cordillera de la costa alcanza alturas cercanas a los 1000 msnm, mientras que desde el mismo río hacia el Sur, esta casi desaparece, alcanzando alturas máximas de $300 \mathrm{msnm}$-aunque a partir del río Toltén, la cordillera marítima comienza nuevamente a ascender en altitud ${ }^{26}$. Finalmente, el valle central, de "mayor valor ecuménico" y de "más amplia superficie", se caracteriza por poseer un relieve que puede sobrepasar los 300 y hasta $500 \mathrm{msnm}^{27}$. Esta es una estructura fuertemente influenciada por la cordillera de la costa y de los Andes. De los Andes ha recibido depósitos volcánicos y aluviales decisivos-gracias a las dos importantes cuencas del Toltén y del Imperial-en la conformación de sus suelos; y, por la cordillera de la costa, ha visto su clima adquirir rasgos de semicontinentalidad al obstruir el paso de las lluvias provenientes del

\footnotetext{
${ }^{24}$ No se entrará en detalles acerca de lo que significó la ocupación de La Araucanía, por ser un hecho ya ampliamente tratado por la literatura histórica de Chile. Véase por ejemplo Pinto, Jorge. 2000. La formación del Estado y la nación y el pueblo mapuche. De la inclusión a la exclusión, Santiago, Ediciones de la Dirección de Bibliotecas, Archivos y Museos.

${ }^{25}$ Espinoza, Eduardo. 1897. Geografía descriptiva de la República de Chile, Santiago, Imprenta Barcelona, pp. 404412.

${ }^{26}$ Mardones, M. 2005. "La Cordillera de la Costa: caracterización físico-ambiental y regiones", en Smith-Ramírez, Cecilia; Armesto, Juan y Valdovinos, Claudio (editores), Historia, biodiversidad y ecología de los bosques costeros de Chile, Santiago, Editorial Universitaria, pp. 39-60.

27 Instituto Geográfico Militar. 1986. Geografía de Chile. IX región de La Araucanía, Santiago, Instituto Geográfico Militar, p. 66.
} 
Pacífico ${ }^{28}$. En cualquier caso, el departamento de Imperial se haya en la latitud en que comienza el clima templado lluvioso, en Chile, con lluvias anuales que pueden ir desde los 1.000 a $2.000 \mathrm{~mm}$, sin estación seca ${ }^{29}$. Este clima húmedo ha favorecido la existencia, en el territorio, de los bosques caducifolios, ricos en especies higrófilas, como el coihue (Nothofagus dombeyi), roble (Nothofagus obliqua) y raulí (Nothofagus alpina) ${ }^{30}$. Este es un bosque que, como se verá, hacia el siglo XIX imperaba en la cordillera de la costa y en gran parte del valle central. Junto a este bosque, se encuentra una fauna compuesta por aves como la torcaza (Columba araucana) y el chucao (Scelorchilus rubecula), y mamíferos como el puma (Puma concolor) y el pudú (Pudu puda), entre otras especies ${ }^{31}$.

Ha sido esta diversidad de ecosistemas y recursos naturales lo que convierte al departamento de Imperial en un área interesante de estudiar. En el presente trabajo se hablará de borde costero o litoral para referirse, al mismo tiempo, a la cordillera de la costa y a la franja litoral, mientras que el valle central abarcará las zonas restantes del territorio y que se encuentran al oriente del borde costero (Figura 1).

\section{Fuentes de información}

Para analizar la influencia del medio ambiente sobre la inmigración del departamento de Imperial, se recopilaron y analizaron fuentes primarias-diarios de viajeros, naturalistas, exploradores y funcionarios de gobierno-y secundarias -estudios históricos y geográficos-. Estas fueron sometidas a una crítica interna y externa para evaluar la calidad de la información entregada por ellas. En otras palabras, se puso atención al contexto en el que las fuentes fueron producidas $\mathrm{y}$ al mensaje que intentaron proyectar ${ }^{32}$. Fue fundamental la revisión de documentos almacenados en el Archivo Regional de la Araucanía, el Archivo Nacional de Santiago y la Biblioteca Nacional de Chile. Además, se visitaron bibliotecas locales para encontrar trabajos de historia relacionados con poblados que no suelen aparecer en los archivos oficiales, como Quepe, Freire, Radal y Pitrufquén. Gracias a una exposición temporal acerca de fotografías de Chol-Chol, entre los años de 1915 y 1930, en el Museo Regional de La Araucanía, Temuco, se pudo obtener más información de esta localidad. El trabajo de gabinete fue complementado con trabajo de campo para estimar cualitativamente los cambios y continuidades en el medio ambiente del área de estudio.

\footnotetext{
28 ídem.

${ }^{29}$ Chester, Sharon. 2016. Flora y Fauna de Chile. Guía de Identificación, Barcelona, Lynx, p. 47.

30 Ídem.

${ }^{31}$ Instituto Geográfico Militar. 1986. Biogeografía, Santiago, Instituto Geográfico Militar, pp. 101-105.

32 Merello, Ítalo. 1988. Historia del derecho, Valparaíso, Ediciones Universidad Católica de Valparaíso, pp. 21-22; Bartram, Rob. 2010. "Geography and the Interpretation of Visual Imagery", en Clifford, Nicholas; French, Shaun y Gill Valentine (editores), Key Methods in Geography, Los Angeles, Sage publications, pp. 131-140.
} 
Figura 1. Área de estudio. (A) Borde costero o litoral; (B) Depresión intermedia o valle central.

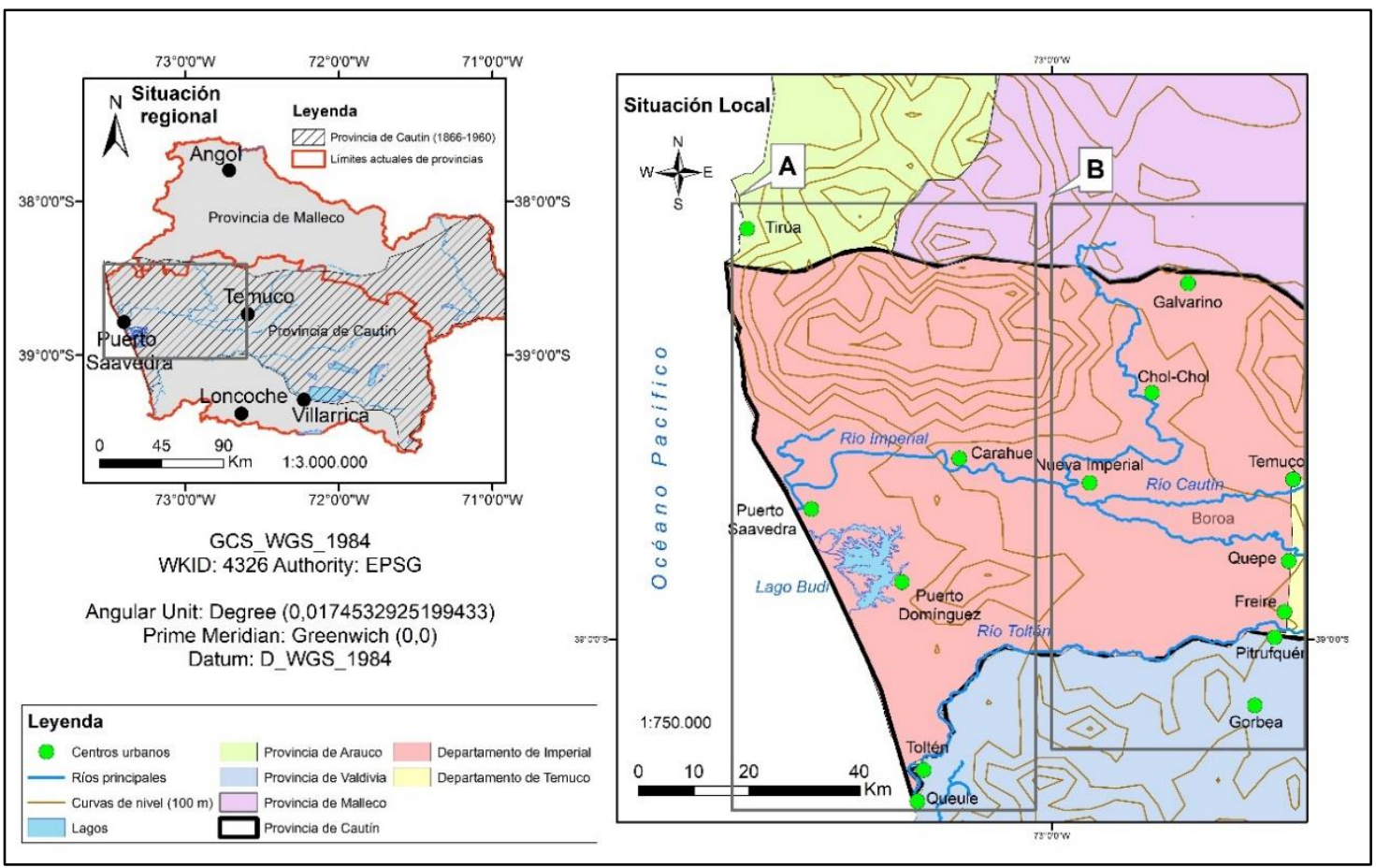

Fuente: Elaboración propia.

Cabe destacar que la disponibilidad de fuentes oficiales del departamento de Imperial definió la escala temporal del siguiente estudio. Hay especial abundancia de fuentes a partir de la ocupación del borde costero, en 1866 con la fundación de Queule, hasta el año de 1920. Sin embargo, luego de esta última fecha, no se halló documentación originada en el departamento. Al parecer, es información que se encuentra extraviada.

\section{Resultados y discusión}

\section{El medio ambiente se impone en el borde costero}

En la segunda mitad del siglo XIX la técnica estaba dotando al ser humano de instrumentos para superar, en gran medida, las constricciones geográficas impuestas por el medio. La creciente navegación a vapor, el incremento de líneas férreas en el mundo y el desarrollo de la medicina, entre otros avances, estaban constituyendo, para numerosos observadores de la época, evidencias de que el ser humano estaba, al fin, controlando a la naturaleza-o al menos acercándose a su control- ${ }^{33}$. Sin embargo, esta aparente historia de triunfo occidental no

\footnotetext{
${ }^{33}$ Hobsbawm, Eric. 2007. La Era del Capital, 1848-1875, Barcelona, Editorial Crítica, pp. 202-217; Hobsbawm, Eric. 2007. La Era del Imperio, 1875-1914, Barcelona, Editorial Crítica, pp. 252-271.
} 
debe ocultar el hecho de que los fracasos humanos ante el medio ambiente o de imposición de este último sobre el primero seguían existiendo. Quizás donde de mejor forma se vio esta situación fue en las zonas fronterizas de los estados occidentales en expansión ${ }^{34}$. Fue, por lo general, aquí, donde el hombre blanco entró en contacto con ecosistemas todavía desconocidos, poniendo a prueba su capacidad de adaptación y de entendimiento del medio ambiente que enfrentaba ${ }^{35}$. Si bien, el imperialismo europeo de la época puede ejemplificar exitosamente estos procesos, algo similar se puede ver también con Chile y su expansión en La Araucanía $^{36}$. Aquí el Estado, en general, desconocía al medio ambiente natural que pretendía conquistar, teniendo que adaptar sus estrategias de ocupación no solo para enfrentar al mapuche que se resistía al avance chileno, sino que, también, para superar distintos obstáculos naturales que se interponían a la fundación de ciudades y a la instalación de los $\operatorname{colonos}^{37}$. En este sentido, la colonización del borde costero de La Araucanía puede servir de ejemplo, pues aquí las fuentes sugieren que el clima, los ríos y los bosques obstaculizaron de manera seria la llegada del Estado chileno.

El clima lluvioso del borde costero y la propensión de ciertos lugares a inundarse por la crecida de los ríos, hizo compleja su habitabilidad. Todo indica que los ríos del departamento, al menos el Imperial y el Toltén, tendían a salir de sus cauces en invierno ${ }^{38}$. Es posible que estas crecidas se hayan debido más a causas naturales que a causas humanas. En efecto, la evidencia sugiere que el terreno que bordea a dichos ríos, en su curso inferior, se habría visto proclive a aluviones invernales gracias a la subsidencia del suelo ocasionado por los terremotos y los

\footnotetext{
${ }^{34}$ Hobsbawm, Eric. 2007. La Era del Imperio, pp. 252-271.

${ }^{35}$ Kenny, Judith. 1995. "Race, and Imperial Authority: The Symbolic Landscape of the British Hill Station in India", en Annals of the Association of American Geographers, no 4, vol. 85, Cambridge, pp. 694-714; Livingstone, David. 1999. "Tropical climate and moral hygiene: the anatomy of a Victorian debate", en The British Journal for the History of Science, no1, vol. 32, Cambridge, pp. 93-110; Pratt, Mary. 2010. Ojos imperiales. Literatura de viajes y transculturación, México D.F., Fondo de Cultura Económica, pp. 363-387.

${ }^{36}$ En América Latina se vivieron situaciones similares durante la expansión de los estados nacionales. Véase por ejemplo: Klug, João. 2017. "Da Aelamanha para a floresta subtropical brasileira: as propostas do Dr. Paul Aldinger para as colônias alemãs no sul do Brasil", en História e Migrações. Diálogos, Marcos Gerhardt, Eunice Sueli Nodari y Samira Peruchi Moretto (orgs.), São Leopoldo, Oikos editora, pp. 45-63; Leal, Claudia. 2019. "Selvas: amenazantes y amenazadas", en Un pasado vivo. Dos siglos de historia ambiental latinoamericana, Claudia Leal, John Soluri y José Augusto Pádua (eds.), México D.F., Fondo de Cultura Económica, pp. 127-149.

${ }^{37}$ El historiador Matías González ha ejemplificado este difícil proceso de ocupación con el batallón de zapadores, fundado en 1877, para hacer frente, en parte, a los obstáculos naturales que existían en la región. El batallón debió derribar bosques, construir puentes y desecar pantanos, entre otras labores, para abrir caminos y levantar ciudades. González, Matías. 2020. "Civilizing Nature with the Spade and the Rifle: The Engineer Battalion in the Araucanía Region, Chile (1877-1891)". Environment \& Society Portal, Arcadia (Spring 2020), no 21. Rachel Carson Center for Environment and Society. http://www.environmentandsociety.org/node/9043.

${ }^{38}$ Biblioteca Nacional de Chile (en adelante BN), Sección Mapoteca, Francisco Vidal Gormaz, "Plano del río Toltén i plaza militar del mismo nombre. Levantado de orden del Supremo Gobierno", 1866-1867.
} 
tsunamis que azotaron a la zona a lo largo de su historia-al menos desde $1575-{ }^{39}$. De hecho, cartografía de la época muestra que las riberas del Imperial y del Toltén eran ya vegas inundables al momento de la colonización chilena, paisaje que todavía hoy se puede apreciar en las riberas de ambos ríos ${ }^{40}$. Tener en cuenta esta cualidad inundable e histórica del paisaje no es de menor importancia, pues sería indicio de que no necesariamente por razones antrópicas se desarrollaron inundaciones-por ejemplo, a través de la tala maderera y la consecuente sedimentación de los cauces de los ríos-. Por otro lado, las fuentes sugieren que por aquellos años el nivel de precipitación era alto, facilitando la ocurrencia de aluviones invernales. Los niveles de precipitación habrían sido como en Valdivia, no dejando de llover inclusive en verano ${ }^{41}$. En la tabla 1 se representa la información colegida desde las fuentes documentales. Con una equis se han marcado los años copiosos en lluvia. Para sostener esta posibilidad se asumió que la misma intensidad de las precipitaciones llevó a que fuesen registradas por las autoridades, viajeros y científicos que se encontraban en el departamento durante las respectivas fechas. Al contrario, los años en blanco serían años con la lluvia suficiente como para no llamar la atención de los informantes. Estas suposiciones, de ser correctas, podrían estar avaladas, además, por el hecho de que cuando había sequía, quedaba registrado en los documentos, tal como sucedió en 1889.

Desde un principio esta realidad ambiental habría afectado a la inmigración en Toltén y Queule. Cornelio Saavedra, comandante de las operaciones de la Frontera, se refiere a los inmigrantes en su memoria con cierto tono de lamento: "Inmensamente mayor habría sido su número si la estación no hubiese sido tan avanzada; pues me consta que muchos han diferido su traslado hasta el verano próximo a causa de las lluvias que tanto se anticipan en estos lugares" ${ }^{\prime 4}$. Si bien, en verano los caminos podían ser transitados cómodamente, en los meses lluviosos-que eran la mayoría-se volvían "intransitables" ${ }^{48}$. Las inundaciones serían la continua queja de las autoridades locales en esta zona meridional del borde costero. En 1883, según la autoridad máxima de Toltén, el río inundaba las casas hasta en un metro ${ }^{49}$. Hacia 1900, el subdelegado de Toltén escribía en su memoria que era "urgente reparar el edificio del telégrafo por los "ventarrones y por las grandes avenidas y las aguas apiladas a causa del viento" ${ }^{50}$. La conjunción de estos factores llevó a decir a Alejandro Holzappel, gobernador del

\footnotetext{
${ }^{39}$ Cisternas, Marco; Atwater, Brian F.; Torrejón, Fernando; Sawai, Yuki; Machuca, Gonzalo; Lagos, Marcelo; Eipert, Annaliese; Youlton, Cristián; Salgado, Ignacio; Kamataki, Takanobu; Shishikura, Masanobu; Rajendran, C. P.; Malik, Javed K.; Rizal, Yan; Husni, Muhammad. 2005. "Predecessors of the giant 1960 Chile earthquake", en Nature, vol. 437, London, pp. 404-407; Stewart, Daniel. 2019. "Historical tsunamis in the Concepcion bay, as seen in the reconstructed flood levels from the colonial city of Concepcion (Penco), Chile (1570-1835)", en Revista de Historia, no26, vol. 2, Concepción, pp. 97-127.

${ }^{40}$ BN, Sección Mapoteca, Francisco Vidal Gormaz, "Plano del río Toltén i plaza militar del mismo nombre. Levantado de orden del Supremo Gobierno", 1866-1867; BN, Sección Mapoteca, Leoncio Señoret, "Esploracion del río Imperial hecha bajo las órdenes del capitán de navío", julio de 1869.

${ }^{41}$ Chaigneau, Federico. 1896. "Viaje al río Imperial", p. 51.
} 
departamento de Imperial, en una fecha temprana como 1882, que "fácil es convencerse que el Departamento de La Imperial, en lugar de ir delante de año en año va decayendo. Toltén desde su fundamento no ha tenido vida propia porque los terrenos que lo rodean no se prestan para la agricultura y en mayor parte se aniegan [sic] en el invierno. La vida artificial que ha llevado solo ha sido sostenida por las entradas de la Tropa que ha tenido guarnición" ${ }^{51}$.

Tabla 1. Años lluviosos en el Departamento de Imperial, 1866-1915.

\begin{tabular}{|c|c|c|c|c|c|c|c|c|c|}
\hline 1866 & 1867 & 1868 & 1869 & 1870 & 1871 & 1872 & 1873 & 1874 & 1875 \\
\hline $\mathrm{X}$ & $\mathrm{X}$ & & & & & & & & \\
\hline 1876 & 1877 & 1878 & 1879 & 1880 & 1881 & 1882 & 1883 & 1884 & 1885 \\
\hline & & & & & $\mathrm{X}$ & $\mathrm{X}$ & & & \\
\hline 1886 & 1887 & 1888 & 1889 & 1890 & 1891 & 1892 & 1893 & 1894 & 1895 \\
\hline 1896 & 1897 & 1898 & 1899 & 1900 & 1901 & 1902 & 1903 & 1904 & 1905 \\
\hline $\mathrm{X}$ & $\mathrm{X}$ & $\mathrm{X}$ & $\mathrm{X}$ & $\mathrm{X}$ & $\mathrm{X}$ & $\mathrm{X}$ & $\mathrm{X}$ & $\mathrm{X}$ & $\mathrm{X}$ \\
\hline 1906 & 1907 & 1908 & 1909 & 1910 & 1911 & 1912 & 1913 & 1914 & 1915 \\
\hline $\mathrm{X}$ & & & $\mathrm{X}$ & $\mathrm{X}$ & & & & & \\
\hline
\end{tabular}

Fuentes: Verniory, Gustav. 2001. Diez años en La Araucanía, 1889-1899, Santiago, Pehuén editores, pp. 1-490; Chaigneau, Federico. 1896. "Viaje al río Imperial”, p. 51; Saavedra, Cornelio. 2009. Documentos, pp. 91-243; BN, Sala Medina, Carta de Broca Lavie a Manuel Rivas Vicuña, Toltén, 1910, s/f; ARA, MM, 1885, vol. 53, p. 316; ARA, MM, 1890, vol. 54, p. 375; ARA, Gobernación de Imperial, Nueva Imperial, 1905, vol. 9, pp. 447-454; ARA, Gobernación de Imperial, Nueva Imperial, 1913, vol. 24, s/f; AHN, Intendencia de Valdivia, Valdivia, 1900, vol. 129, pp. 233-234; ARA, Gobernación de Imperial, Nueva Imperial, 1915, vol. 29; ARA, Gobernación de Imperial, Nueva Imperial, 1914, vol. 27, pp. 207-226; ARA, Gobernación de Imperial, Nueva Imperial, 1916, vol. 30, p. 285.

Producto de la excesiva lluvia, el río Imperial también causó estragos en los asentamientos ribereños. Sin embargo, no se descarta que la tala excesiva de bosque en las riberas del río Imperial y del río Chol-Chol, tributario del primero, haya contribuido a las inundaciones en esta parte del departamento ${ }^{61}$. En julio de 1904 la crecida del río Imperial habría afectado a cerca

${ }^{61}$ El gobernador del departamento de Imperial se quejó en 1905 de que la excesiva tala forestal en las riberas del río Chol-Chol estaba ocasionando las crecidas del río y la consecuente inundación en la ciudad de Nueva Imperial. ARA, Gobernación de Imperial, Memoria del Gobernador, Nueva Imperial, 30 de marzo de 1905, vol. 9, pp. 447-454. 
de 500 personas entre Carahue y Bajo Imperial, provocando mortandad de animales y dejando "campos en ruinas". Según un comunicado oficial, "ahora solo se ven indigentes por las calles de las ciudades de la primera subdelegación"62. Los efectos de la crecida del Imperial habían sido tan graves como los de $1899^{63}$. En 1915 se informaba que las comunidades indígenas de Bernardo Henunte y Cura Raín, en la desembocadura del río Imperial, habían sido seriamente afectadas por eventos climáticos: "en el invierno la bravura del mar y las crecidas del río barrió con toda la cobertura vegetal de su posesión, dejando arena en el suelo que hizo de sus terrenos incultivables y sin pastos para sus animales". De tal manera que, de acuerdo al informe del subdelegado: "si no cambian de lugar, perecerán"64.

Llama la atención la permanencia de habitaciones indígenas en terrenos expuestos a inundaciones destructivas. El mapuche solía escoger lugares inundables para favorecer a sus cultivos $^{65}$. De hecho, todo indica que podía poseer un conocimiento acabado de las crecidas de cursos o cuerpos de agua ${ }^{66}$. Por lo tanto, el que haya habido familias mapuche negativamente afectadas por inundaciones como la de 1915, en el río Imperial, refuerza la idea de que las inundaciones estaban teniendo magnitudes inusuales, probablemente por la creciente sedimentación de los cauces producto de la tala forestal. No se encontraron registros de sucesos catastróficos similares en el río Toltén. Es plausible pensar que la misma ausencia de tala intensiva en las riberas de este río favoreció a la no ocurrencia de inundaciones desastrosas.

Además del clima lluvioso del borde costero, el bosque también impuso su presencia al ser humano. Saavedra escribe en su memoria que, sumada a la inseguridad de los campos producto de la guerra entre el Estado de Chile y los mapuche:

"Otra de las causas poderosas que han impedido la inmigración, ha sido la absoluta falta de madera de construcción; porque aunque hay en las inmediaciones magníficos bosques, no hay todavía sino muy pocos trabajadores que se dedican a su labranza, y estos pocos han estado ocupados con preferencia en proporcionar el material para los edificios fiscales" ${ }^{\prime 67}$.

\footnotetext{
62 El departamento de Imperial se dividía en subdelegaciones.

${ }^{63}$ ARA, Gobernación de Imperial, Nueva Imperial, 1904, vol. 51, fs. 140-143.

${ }^{64}$ ARA, Gobernación de Imperial, Nueva Imperial, 1915, vol. 29, p. 487.

${ }^{65}$ Otero D., Luis. 2006. La huella del fuego. Historia de los bosques nativos. Poblamiento y cambios en el paisaje del sur de Chile, pp. 42-44.

${ }^{66}$ El teniente de marina Francisco Vidal Gormaz describe con detalle la estrategia ocupada por una comunidad mapuche que vive cerca de la desembocadura del río Budi, en el lago Budi, para evitar que crezcan las aguas y pongan en peligro sus viviendas. La misma estrategia les sirve para capturar gran número de peces. ARA, Memorias Ministeriales (en adelante MM), Documentos, G., Esploracion hidrografica de la costa de Arauco, Estracto de Diario, Santiago, 30 de abril de 1867, vol. 1, pp. 156-157.

${ }^{67}$ Saavedra, Cornelio. 2009. Documentos, p. 114
} 
Agregando más adelante:

"Pero el principal inconveniente que se presenta, por ahora, es la falta de terrenos aptos para el cultivo en inmediaciones de la plaza, porque los que hay están todos en poder de los indios [...] Aquellos lugares son muy montuosos [continúa Saavedra] y apenas en algunas partes, sobre todo a orillas de los ríos, se encuentran praderas de algunas extensiones, y es allí donde los indios tienen sus casas y sembrados y allí también donde mantienen sus animales, porque los montes, a consecuencia de lo bajo del terreno, son poco aptos para la crianza de ganados, sobre todo en el invierno, cuando se convierten en grandes aguazales"68.

Algo similar ocurrió en la zona del interfluvio Imperial-Toltén, específicamente en torno al lago Budi. Allí los bosques imperaban y la escasa tierra disponible se hallaba en manos mapuche, de modo que, en 1902, cuando se trajeron colonos españoles a vivir en la zona, se iniciaron numerosos pleitos en torno a los límites de las propiedades, pues el número de tierras entregadas a los colonos no había sido suficiente. El bosque, de hecho, habría causado tal impacto en los colonos, que según un oficio departamental, habían temido internarse al mismo, dejando en manos de los jornaleros chilenos las labores de despeje ${ }^{69}$. Estos problemas continuaron hasta, al menos, el año $1917^{70}$. Con todo, una emergente colonia española se inició con la fundación de Puerto Domínguez, en 1902, a orillas del lago Budi. La colonia vivió de la explotación del bosque nativo y de la agroganadería, siendo el mismo lago usado como vía de transporte para pasajeros y productos. La madera fue llevada a lugares tan lejanos como Chol-Chol ${ }^{71}$.

La sección costera que va desde la desembocadura del río Imperial hasta Tirúa también habría estado mayoritariamente cubierta de bosque. Solamente las riberas del río Moncul habrían estado más despejadas de vegetación por los habitantes indígenas y colonos allí instalados que explotaban los bosques y cultivaban trigo, la cebada, frijoles y papas ${ }^{72}$. En Tirúa, algunas comunidades mapuche habrían existido en la desembocadura del río Tirúa, siendo el resto del territorio bosque ${ }^{73}$. Aún en 1913 el bosque parecía predominar en el paisaje. El subdelegado de Nehuentúe informaba al Gobernador que: "este suelo está compuesto mayormente de montañas vírgenes [...] sin ocupaciones de nadie, con excepcion de partes

\footnotetext{
68 Ibíd., pp. 114-115.

${ }^{69}$ ARA, Gobernación de Imperial, 1904, vol. 33, pp. 353-367.

70 BN, "El Budi i Colonos nacionales" El Diario Austral, , 29 de mayo de 1917, p. 4.

${ }^{71}$ Villalba, Álvaro. 2013. "Conflicto político y social en la Araucanía a principios del siglo XX", pp. 122-157.

72 ARA, Gobernación de Imperial, Nueva Imperial, 17 de abril de 1915, vol.29, pp. 192-193.

73 Domeyko, Ignacio. 2010. La Araucanía y sus habitantes, Santiago, Biblioteca Fundamentos de la Construcción de Chile, p. 23.
} 
menos montañosas, donde residen algunos pobladores"74. Lo boscoso y apartado del lugar debieron desalentar la colonización de esta parte del borde costero.

Sin embargo, en las riberas del río Imperial, entre Carahue y Puerto Saavedra, la colonización parece haber hallado las mejores condiciones para proliferar. Las riberas del río constituían, en su mayoría, vegas y praderas, por lo que no había un bosque predominante que despejar para poder asentarse. Además, el tráfico comercial establecido a lo largo de la cuenca del Imperial servía de estímulo para asentarse en las cercanías de esta red fluvial. No por nada la principal ruta caminera del borde costero se trazó entre Temuco y Carahue ${ }^{75}$. A pesar de las crecidas del río y de eventos catastróficos como terremotos y tsunamis, la población persistió en el lugar ${ }^{76}$.

Ciertamente la influencia del bosque en la distribución de asentamientos humanos no debe ser exagerada. El mapuche, desde tiempos prehispánicos, venía conviviendo con ellos para recolectar frutos y cazar animales propios del bosque templado que existía en el departamento de Imperial $^{77}$. De hecho, no se descarta que el mapuche haya usado el fuego para abrir la enmarañada vegetación que caracteriza al bosque chileno en estas latitudes ${ }^{78}$. Sin embargo, no se debe olvidar que el argumento de este trabajo se centra en los colonos o inmigrantes y no en los indígenas. Al fin y al cabo, prácticamente la totalidad de los colonos eran extranjeros de La Araucanía-incluyendo a los chilenos-de modo que su forma de percibir a los bosques y de interactuar con ellos debió ser muy distinta a la de los mapuche ${ }^{79}$.

La geohistoria del borde costero impuso incluso problemas a la burocracia estatal encargada de gestionar la instalación de los colonos $^{80}$. Las vías de comunicación eran escasas y su construcción parecía no ir a la par del crecimiento demográfico local. En los registros se ven

\footnotetext{
${ }^{74}$ ARA, Gobernación de Imperial, Nueva Imperial, 1913, Vol.27, p. 342.

${ }^{75}$ ANH, Ministerio de Obras Públicas, Mapa caminero de Chile, 1904, vol. 00853, p. 192.

${ }^{76}$ En 1877 ocurrió un terremoto y un tsunami que afectó al borde costero de La Araucanía. BN, Sección Periódicos, Algunos datos relativos al terremoto del 9 de mayo de 1877, i a las agitaciones del mar, Santiago, Imprenta nacional, p. 4-6.

77 Aldunate, Carlos. 1997. "En el país de los lagos, bosques y volcanes", en Chile antes de Chile, prehistoria, Santiago, Museo Chileno de Arte Precolombino, 1997, pp. 59-67.

78 Smith, Edmund. 1914. Los Araucanos. Notas sobre una gira efectuada entre las tribus indígenas de Chile Meridional. Santiago, Imprenta Universitaria, p. 113.

${ }^{79}$ Matías González y Fernando Torrejón han argumentado, con numerosa evidencia, de que, en la segunda mitad del siglo XIX, predominaban en el departamento de Imperial actitudes negativas hacia el bosque. Se le veía como un estorbo al progreso y como un lugar que atentaba contra el bienestar del ser humano. Estas expresiones provenían de viajeros europeos y de chilenos que, en general, no estaban acostumbrados a un medio ambiente como el de La Araucanía. En todo caso, a inicios del siglo XX comienzan a aparecer voces preocupadas por la conservación del bosque, ya que favorecía a un clima más húmedo y protegía al suelo de la erosión. González M., Matías y Torrejón, F. 2020. "Para construir, comerciar y ¿proteger? La explotación del bosque caducifolio del llano en el antiguo departamento de Imperial (región de La Araucanía), 1867-1920”, en Historia, no53, vol. II, Santiago, (en prensa).

${ }^{80}$ Se entiende por geohistoria a las constricciones que el medio geográfico ha impuesto a la historia del ser humano en América, a través de las selvas, montañas, mares, clima, etc. Véase Cunill, Pedro. 1999. "La Geohistoria”, en Para una historia de América. I. Las estructuras, Carmagnani, Marcello; Hernández, Alicia; y Romano Ruggiero (editores), México, Fondo de Cultura Económica, passim.
} 
numerosos llamados a las autoridades locales a construir y a reparar puentes y caminos entre las distintas localidades costeras ${ }^{81}$. Las crecidas de los ríos destruían los caminos y las lluvias los tornaban intransitables. Entre 1892 y 1915 una balsa particular y no estatal, establecida en el río Toltén, aseguraba el traspaso de los viajeros entre Puerto Saavedra y Toltén ${ }^{82}$. Además, ni siquiera esto garantizaba el traspaso del río. En marzo de 1892, el subdelegado de Toltén escribía al intendente de que le había llegado una nota del indígena Eugenio Millapichún Millatoro avisando de que el balsero Guillermo Gabriel se había rehusado a cruzar sus bueyes, aun cuando había pagado anticipadamente. El subdelegado se apersonó en el lugar de los hechos, y, tras verificar que todo había ocurrido tal cual lo relató Millatoro, recibió la siguiente respuesta por parte del balsero: "ni el Intendente, ni yo, como subdelegado, teníamos derechos de obligarlo a balsear desde esa rivera y con muchas insolencias me agregó que inmediatamente me retirara" 83 .

Aún en 1915, los colonos de las riberas del río Moncul pedían permiso para desarrollar el comercio a lo largo del río, ya que solo así se ayudaría al "progreso" del departamento al no haber caminos para acarrear sus productos ${ }^{84}$.

Sin suficientes vías de comunicación, difícil era que la autoridad ejerciera control sobre el territorio bajo su mando. De aquí que los gobernadores del departamento hicieran constantes llamados al Gobierno central a subdividir aún más el territorio bajo su mando para facilitar su administración. Los argumentos que se esgrimían eran los mismos: terreno montañoso y extenso, inviernos lluviosos y escasez de policías ${ }^{85}$. Incluso hubo ocasiones en que la policía no recibía sueldo ni tampoco comida ${ }^{86}$. Según el Ministro del Interior, en Toltén era urgente regularizar el ejercicio de la justicia, pues no hay policía en el lugar y los carabineros "a menudo interceden en decisiones políticas que no les compete" ${ }^{87}$. Ni siquiera la educación religiosa y chilena se pudo desplegar con facilidad por el territorio. En el lago Budi, las misas tenían poca asistencia por parte de los colonos españoles establecidos alli ${ }^{88}$, y, hacia 1914, el Gobernador del Departamento de Imperial se quejaba del bajo número de escuelas y del recelo con el cual era vista por parte de los niños del departamento, especialmente los indígenas ${ }^{89}$.

\footnotetext{
${ }^{81}$ ARA, Gobernación de Imperial, Nueva Imperial, 1902, vol. 43, s/f; ARA, Gobernación de Imperial, Nueva Imperial, 1917, vol. 31, s/f; ARA, Gobernación de Imperial, Nueva Imperial, 1909, Vol. 62, s/f; ARA, Gobernación de Imperial, Nueva Imperial, 1904, vol. 51, fs. 140-143.

${ }^{82}$ ANH, Intendencia de Valdivia, (ANHIV)Toltén, 1892, vol. 92, s/f; ANHNIV, Toltén, 1915, vol. 229, p. 252.

${ }^{83}$ ANHIV, Toltén, 28 de mayo, 1892, vol. 92, s/f.

${ }^{84}$ ARA, Gobernación de Imperial, Nueva Imperial, 17 de abril de 1915, vol.29, pp. 192-193.

${ }^{85}$ ARA, Gobernación de Imperial, 1904, vol. 9, pp. 736-745; AHN, Intendencia de Valdivia, 8 de marzo de 1900, Vol. 30, p. 312; AHN, Gobernación de Villarrica, 1915, vol. 237, p. 326; ARA, Gobernación de Imperial, 1914, Vol. 27, p. 3.

${ }^{86}$ ARA, Gobernación de Imperial, 1914, vol. 27, p. 390.

${ }^{87}$ ANHIV ,, 11 de marzo de 1909, Valdivia, vol. 195, p. 342.

88 Información personal entregada por el historiador local Hernán Curiñir, 25 de julio, 2011, Temuco.

${ }^{89}$ ARA, Gobernación de Imperial, 1914, vol. 27, pp. 207-225.
} 
No debiera sorprender, entonces, que en el borde costero se hayan registrado numerosos hechos fuera de la ley. Ya a inicios del poblamiento de la región se reconocía esta situación ${ }^{90}$, y en los primeros años del siglo XX estos problemas seguían persistiendo. Al parecer hubo lugares donde la inseguridad era de tal nivel que la población emigró. En un dramático relato, un vecino de Puerto Saavedra pide al gobernador mayor seguridad, porque en su comuna abundan los delincuentes. Según él, ha sido lo apartado de la región lo que ha atentado con la suficiente presencia policial ${ }^{91}$. Vale la pena citar el testimonio completo:

"Señor Gobernador, en mi última visita a su oficina de U.D., le hice presente que el robo tomaba tales proporciones por estas regiones que ya se hacía imposible la vida en los campos y aún en el mismo pueblo. Sería pues necesario ya que U.D. procurará de poner remedio radical a este mal ya endémico. U.D. sabe que aquí no hay ni siquiera para recoger los muchos borrachos botados en la arena; los rateros pues, en el pueblo, llevan la gran vida: hoy es un gallinero que toma el vuelo, mañana los utensilios de una cocina que salen a pasear y no se extrañe que el día menos pensado [¿sepa?] que se han adueñado del convento y de todas sus monjas. De lo que ocurre en el campo ¿qué le diré a UD? Son continuas [¿jeremiados?] que llegan y si debiera anotarlas necesitaría un diario más grande que el 'Mercurio', cuando aparece con las 320 hojas. Es pues indispensable señor Gobernador que nos mande Tropa a esta desamparada región. iUnos cuatro soldados siquiera! En Carahue tienen Carabineros y además de tropa de la policía departamental ¿por qué tanta regalía? Tal vez aquí, porque vivimos algo retirados del centro, de nada necesitamos o ¿nada merecemos? Sírvase pues tomarnos en cuenta, no olvidar que existimos todavía los de Bajo Imperial y antes que los rateros [¿̇glotones?] se adueñen de la Comuna [sic], mandarnos soldados, unos cuatro pacos siquiera" ${ }^{\prime 2}$.

Esta sensación de inseguridad y de abandono por parte del Estado debió ser generalizada, pues las fuentes oficiales del departamento muestran numerosas solicitudes de colonos para portar arma y defenderse de la delincuencia que reina en los campos ${ }^{93}$. Al parecer los mapuche fueron los habitantes más afectados por este contexto, de hecho hubo gobernadores muy preocupados por los colonos que, de manera ilegal, se iban instalando en tierras indígenas ${ }^{94}$.

\footnotetext{
${ }^{90}$ Navarro, Leandro. 2008. Crónica militar de la conquista y pacificación de la Araucanía, desde el año 1859 hasta su completa incorporación al territorio nacional, Santiago, Pehuén editores, p. 130.

${ }^{91}$ ARA, Gobernación de Imperial, Bajo Imperial, 31 de septiembre de 1909, vol. 64, f. 271.

92 Ibíd.

93 ARA, Gobernación de Imperial, Nueva Imperial, 1904, vol. 9, pp. 254, 352-358; ARA, Gobernación de Imperial, Nueva Imperial, 1913, vol. 26, p. 346; AHN, Gobernación de Villarrica, Toltén, 1911, vol. 3, s/f.

94 ARA, Gobernación de Imperial, Nueva Imperial, 1904, vol. 50, f.129; ARA, Gobernación de Imperial, Nueva Imperial, 1914, Vol. 27, p. 231.
} 
La ausencia de mecanismos coercitivos para aplicar la ley también atentó con la actividad maderera y los bosques. Las fuentes muestran constantes robos de madera en los campos, cierre de rutas comerciales por colonos que, de manera tránsfuga, corrieron sus cercos para engrandecer los límites de su propiedad, además de quemas ilegales de bosque para habilitar más tierras de sembradío ${ }^{95}$.

Tabla 2. Estadísticas demográficas del borde costero (1875-1920)

\begin{tabular}{|l|c|c|c|c|c|}
\hline \multicolumn{1}{|c|}{ Poblado } & 1875 & 1885 & 1895 & 1907 & 1920 \\
\hline Toltén & 2.610 & 4.973 & 914 & 2.590 & 2.284 \\
\hline Puerto Saavedra & -- & 523 & 11.479 & 16.991 & 22.876 \\
\hline Carahue & -- & -- & 3.807 & 4.810 & 6.879 \\
\hline
\end{tabular}

Fuente: Dirección General de Estadística. 1931. Resultados del X censo de la población efectuado el 27 de noviembre de 1930 y estadísticas comparativas con otros censos anteriores, Santiago, Imprenta Universo, pp. 44-45.

Las dificultades de poblamiento hasta aquí comentadas parecen estar respaldadas por las cifras demográficas del borde costero. En la tabla 2 solo se han integrado las cifras de esta unidad morfológica. Si bien, se puede observar un general crecimiento poblacional en cada uno de los asentamientos costeros a lo largo de los años-lo que revela, en parte, el éxito de los colonos para adaptarse a los nuevos ambientes ${ }^{101}$ - una puesta en contexto de estas cifras con los datos demográficos del resto de la provincia del Cautín revela un panorama un tanto distinto $^{102}$. En efecto, habría existido una marcada diferencia entre el crecimiento poblacional del borde costero y del valle central, donde la primera estructura morfológica no habría

\footnotetext{
95 ANHIV, Toltén, 1909, vol. 195, p. 342; ARA, Gobernación de Imperial, Nueva Imperial, 1914, Vol. 27, pp. 229, 390; ARA, Gobernación de Imperial, Bajo Imperial, 1909, vol. 64, fs. 271-272; ARA, Gobernación de Imperial, Nueva Imperial, vol. 64, 1909, f. 298.

${ }^{101}$ De acuerdo al historiador Massimo Livi Bacci el éxito de los inmigrantes en establecerse en nuevos territorios se mide, en parte, por su nivel de adaptación ambiental. Livi, Massimo. 2012. Breve historia de las migraciones, Madrid, Alianza Editorial, pp. 15-35.

${ }^{102}$ Es posible que el brusco vaivén poblacional de Toltén hacia 1895 sea evidencia adicional de las dificultades que este poblado estaba teniendo para poder emerger como colonia. Según el ingeniero belga Gustav Verniory, quien visitó Toltén, precisamente, en 1895: "Toltén es un lugar casi muerto. Puede contar con unos 300 habitantes. Hace veinte años era una pequeña ciudad de cierta importancia, sede de una gobernación y de una guarnición, que han sido suprimidas. Se ven buenas casas enteramente abandonadas [...] habría llegado a ser un puerto importante si no fuera por la barra que es muy mala. Los vaporcitos de cabotaje entre Valdivia y Talcahuano tocaban antes en Toltén, pero debían pasar a veces varios días en el mar frente a la barra, esperando una oportunidad para franquearla". Verniory. 2001. Diez años en La Araucanía, p. 384.
} 
contenido tanta población como la segunda (Tabla 3). De hecho, se ve una clara superioridad demográfica de la depresión intermedia a partir de 1885.

Esta diferencia poblacional sería consistente con la idea de que los colonos prefirieron asentarse en el valle central por haber un clima menos lluvioso y por existir una mayor conectividad con el resto del país ${ }^{103}$. Así, no es casualidad que el valle central haya contenido un mayor número de centros urbanos que el borde costero o que la zona pre-andina (Figura 1). Respecto a esta última estructura morfológica, todo parece indicar que vivió una situación similar en términos demográficos (Tabla 3). Aquí la población también fue menor que en la depresión intermedia. Las razones de esta diferencia debieron ser similares a las del borde costero: los colonos preferían zonas con mayor conectividad y sin un clima tan frío y/o lluvioso. Sin embargo, hacia 1907 la zona sub-andina presentó una mayor población que la zona del litoral, probablemente por la conectividad que representó el ferrocarril, que, en 1898, ya llegaba a Pitrufquén ${ }^{104}$. Habría que esperar a 1920 para que el borde costero superara en población a la zona precordillerana de la provincia del Cautín, posiblemente por el impulso que representó la llegada del ferrocarril a Carahue, en $1912^{105}$.

Tabla 3. Panorama demográfico de la región de La Araucanía, según estructura morfológica (1875-1920).

\begin{tabular}{|c|c|c|c|}
\hline Año & Población Borde costero & Población Valle central (a) & Población sub-andina (b) \\
\hline 1875 & 2.610 & 4.346 & Sin datos \\
\hline 1885 & 5.496 & 46.727 & Sin datos \\
\hline 1895 & 16.200 & 85.758 & 10.957 \\
\hline 1907 & 21.832 & 152.953 & 28.785 \\
\hline 1920 & 55.895 & 201.677 & 39.333 \\
\hline
\end{tabular}

Fuente: Elaboración propia. (A) Su sumó la población de las ciudades de Victoria, Perquenco, Lautaro, Galvarino, Temuco, Freire, Loncoche, Gorbea, Pitrufquén y Nueva Imperial. (B) Se sumó la población de Curacautín, Lonquimay, Cunco y Villarrica. Datos entregados por la Dirección General de Estadística. 1931. Resultados del X censo de la población efectuado el 27 de noviembre de 1930 y estadísticas comparativas con otros censos anteriores, pp. 44-45.

\footnotetext{
${ }^{103}$ Ver infra, pp.

${ }^{104}$ Zúñiga, Carlos. 2013. "La explotación del bosque nativo en la zona de Villarrica. Una aproximación desde la historia oral", en Fragmentos de Historia Regional. La Araucanía en el siglo XX, Carlos Zúñiga (compilador), Temuco, ediciones Universidad de la Frontera, pp. 160-200.

${ }^{105}$ Carahue adquiere gran importancia económica para la región al ser ocupado como puerto para la exportación de materias primas a Chile y a otros países. La línea del tren y la ruta fluvial del río Imperial son combinadas para estos propósitos. Véase Flores, Jaime. 2013. "Economía y vías de transportes. La construcción del espacio regional, La Araucanía 1880-1940", en Carlos Zúñiga (compilador), Fragmentos de Historia Regional. La Araucanía en el siglo $X X$, Temuco, ediciones Universidad de la Frontera, pp. 60-75.
} 
Los cálculos realizados en la tabla 3 también parecen avalar la continuidad histórica del poblamiento humano en el litoral de La Araucanía. Los principales poblados siguieron ubicándose a orillas de los dos grandes ríos locales, el Toltén y sobre todo el Imperial (Figura 1). Sin embargo, se infiere de los datos que las montañas boscosas del litoral no fueron escogidas para el asentamiento humano. La cordillera de Nahuelbuta-es decir, desde el río Imperial hacia el Norte- solo posee poblados en sus lomajes más bajos y se podría decir que la cordillera de Mahuidanche-desde el río Imperial hacia el Sur-comenzó a ser colonizada únicamente a través de Puerto Domínguez (Figura 1). Por lo tanto, se podría decir que los bosques y las montañas efectivamente se impusieron al poblamiento a lo largo de los años, determinando, en gran medida, la ubicación de los asentamientos colonizadores.

En síntesis, las constricciones geográficas del borde costero dificultaron la colonización de esta zona, así como la instalación del Estado y su burocracia. Por lo tanto, la idea de que la región de La Araucanía quedó eficazmente articulada al resto del país y su modelo económicoexportador, luego de su incorporación al estado chileno ${ }^{106}$, debe ser vista con cautela, al menos para esta zona de La Araucanía.

\section{Colonizando al medio ambiente en el valle central}

Una historia, un tanto diferente, se puede ver al interior del departamento de Imperial. Si bien, en el valle central los caminos seguían siendo escasos y la inseguridad de los campos y de los poblados parecía superar al Estado, las fuentes sugieren que la colonización del valle central no se vio tan obstaculizada por el medio ambiente como en el borde costero ${ }^{107}$.

Los bosques, en general, no fueron tan densos, por lo que se podía transitar, de un lado a otro, con mayor facilidad. Entre Imperial y Temuco, y entre esta ciudad y Pitrufquén, las fuentes muestran que predominaba un paisaje de parque. Isidoro Errázuriz, ministro del Interior que visitó a lomo de mula el departamento en 1887, cruzó sin mayores problemas el bosque que de vez en cuando aparecía a orillas del río Cautín, entre Nueva Imperial y Temuco ${ }^{108}$. Algo similar apreció René Le Feuvre cuando visitó la región por una plaga de langostas, en 1891, y recorrió desde Pitrufquén a Temuco, la capital provincial. Lo que él vio fue fundamentalmente un paisaje agrario, sinónimo, según él, de progreso y de seguridad para el habitante. Luego de haber dejado la boscosa provincia de Valdivia, escribe:

"El aspecto y la naturaleza de los terrenos, la bondad del clima, los extensos campos completamente desmontados, etc., auguran un brillante porvenir a la agricultura en estas

\footnotetext{
106 Flores, Jaime. 2013. “Economía y vías de transportes. La construcción del espacio regional, La Araucanía 18801940", pp. 60-75.

107 En la memoria del gobernador, se señalaba que Chol-Chol y Boroa se estaban despoblando producto de la inseguridad de los campos. ARA, Gobernación de Imperial, Nueva Imperial, 1915, vol. 29, pp. 66-100.

${ }^{108}$ Errázuriz, Isidoro. 2010. “Tres Razas”, en Revista Andes del Sur, 2, Temuco, p. 72.
} 
regiones, como lo están manifestando los numerosos cultivos que a cada paso se encuentran ahí. División de la propiedad, capitales, seguridad y buenas vías de comunicación, he aquí lo que haría que esta región fuera una de las más ricas de nuestro país"109.

Es verdad que en el valle central aún existían zonas con un denso bosque-y aún hoy se pueden observar relictos de este bosque antiguo en el paisaje local-. Según el ingeniero belga Gustav Verniory, quien visitó la región a fines del siglo XIX, entre el río Quepe y Freire existía un terreno "accidentado y boscoso"110, y algo similar se podía ver desde la cordillera de la costa hasta las inmediaciones de Gorbea, un poco más al Sur del río Toltén ${ }^{111}$. Sin embargo, todo indica que estas eran las únicas zonas con un predominio de bosque. El resto habría sido paisaje de parque o campos de cultivo como los vistos por Le Feuvreau. Un dibujo hecho por el viajero estadounidense Edmund Reuel Smith, en 1849, de la zona de Boroa, entre el río Cautín y Quepe, ayuda a imaginar el tipo de paisaje que predominaba en esta zona, uno donde el bosque denso y enmarañado no era la nota común (Figura 2). La antigua presencia humana en el lugar se había encargado de producir este tipo de paisaje ${ }^{112}$.

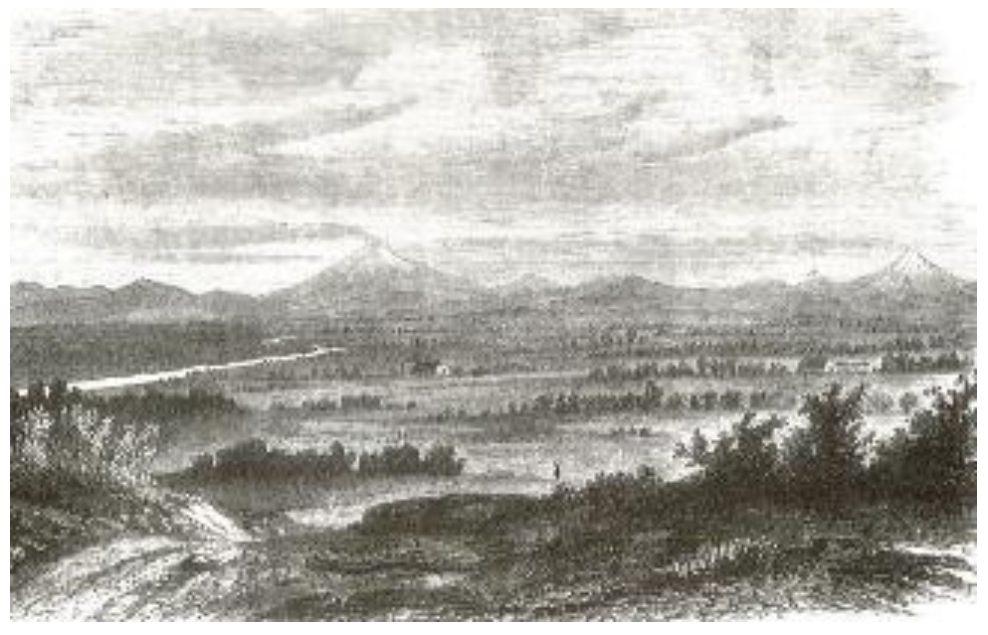

Figura 2. Vista de Boroa desde cerro Cancura. Fuente: Smith, Edmund. 2016. "Los araucanos. Notas sobre una gira efectuada entre las tribus indígenas de Chile meridional", en Travesías por La Araucanía: relatos de viajeros de mediados del siglo XIX, Ítalo Salgado (compilador), Temuco, Ediciones Universidad Católica de Temuco, p. 122.

\footnotetext{
${ }^{109}$ AHN, Fondo Ministerio de Obras Públicas, vol. 00587, p. 7

${ }^{110}$ Verniory. 2001. Diez años en La Araucanía, p. 381.

111 Ibid., p. 384.

${ }^{112}$ Se podría decir que desde tiempos prehispánicos hasta fines del siglo XVI las riberas del río Imperial, del río Cautín y del río Quepe se encontraron habitadas por una ingente cantidad de indígenas. Bengoa, José. 2008. Historia del pueblo mapuche: siglos XIX y XX, Santiago, Lom ediciones, pp. 22-23. Además, existen numerosos testimonios de viajeros que en el siglo XIX declaran haber visto, en esta suerte de Mesopotamia, señales de una antigua y densa población indígena. Véase: Schmutzer S., Karin. 1981. "Aventuras de un inglés en Chile. Guillermo Watkins, 18381880", p. 110. Disponible en: https://repositorio.uc.cl/handle/11534/9618. [fecha de consulta: 2 de abril de 2019]; Errázuriz, Isidoro. 2010. "Tres Razas", p. 58. Este proceso de cambio de paisaje fue muy similar al ya estudiado en la actual región de Los Ríos. Véase: Camus, Pablo y Solari, María. 2008. "La invención de la selva austral. Bosques y tierras despejadas en la cuenca del río Valdivia (siglos XVI-XIX)", en Revista de Geografía Norte Grande, vol. 40, Santiago, pp. 5-22.
} 
De hecho, las fuentes sugieren que, con los años, este tipo de paisaje se iba extendiendo cada vez más a lo largo del valle central. Bastaron solo diez años-es decir, desde 1889 a 1899para que la selva existente entre Temuco y Lautaro desapareciera producto del tendido ferroviario-y algo similar estaba ocurriendo con el bosque que se extendía desde el río Quepe hasta el río Toltén ${ }^{113}$. Al otro lado de este río, en Pitrufquén, la explotación maderera estaba extrayendo los troncos que al menos desde inicios del siglo XIX imperaban en el lugar ${ }^{114}$. En el sector de Faja Maisan, en la ribera sur del río Toltén, cerca de Pitrufquén, los colonos alemanes a fuerza de hacha y de fuego despejaban los bosques que cubrían sus campos hoy dedicados al cultivo y la ganadería ${ }^{115}$; y, en Quepe, los colonos mayoritariamente chilenos, también hacían retroceder al bosque mediante las mismas técnicas ${ }^{116}$. En 1904, la memoria del gobernador del departamento mostraba el número de hectáreas dedicadas al cultivo, pudiéndose ver que era justamente la zona del valle central, a través de Nueva Imperial y Galvarino, la que lideraba las cifras. Lamentablemente no se encontraron datos similares para otros años (Tabla 4).

Tabla 4. Hectáreas sembradas en el departamento de Imperial, 1904

\begin{tabular}{|c|c|c|}
\hline & Trigo & Cebada \\
\hline Nueva Imperial & 7.000 & 5.000 \\
\hline Galvarino & 12.000 & 200 \\
\hline Bajo Imperial & 800 & 400 \\
\hline Nehuentúe & 547 & \\
\hline
\end{tabular}

Fuente: ARA, Gobernación de Imperial, vol. 9, 13 de abril, 1904, f. 92.

El fuego era el medio predilecto para destruir al bosque. Así se obtenían más hectáreas de suelo cultivable, como también un suelo más productivo. Verniory explica que:

“El roce consiste en cortar el boscaje inferior y entresacar los árboles durante el invierno. Cuando el sol del verano ha secado todo, se quema la selva para enseguida cultivar el suelo. El humo natural centenario y las cenizas forman un terreno excelente para producir trigo durante varios años sin otro trabajo que la siembra. Los grandes árboles que han resistido el incendio están muertos y semicalcinados, pero permanecen de pie"117.

\footnotetext{
${ }^{113}$ Verniory. 2001. Diez años en La Araucanía, p. 485.

${ }^{114}$ Beissinger, Frantz; Cerda, Eduardo; Mansilla, Juan; y Ramsés Sepúlveda. 1999. Pitrufquén: Entre la historia y la memoria, Pitrufquén, Ilustre Municipalidad de Pitrufquén, p. 97-113.

115 Biblioteca Municipal de Pitrufquén, Bélgica Velásquez, s/a, Faja Maisan, s/f.

${ }^{116}$ Varios autores. 2014. Voces Ancestrales. Cuentos de Quepe, Freire, RENDCL Impresiones, pp. 11-13.

117 Ibíd., p. 485.
} 
Los colonos fueron expertos en esta técnica, pudiendo llegar a despejar, en los primeros años, siete hectáreas por familia ${ }^{118}$. Las fuentes sugieren que fue en el valle central donde se concentró, con mayor intensidad, el roce del bosque, ya que los testimonios escritos y visuales parecen provenir, en su mayoría, de este lugar del departamento ${ }^{119}$. Después de todo, la topografía local, mayormente plana, facilitaba el uso del fuego en contra de la vegetación.

Además de los bosques, los ríos de la zona tampoco parecen haber generado problemas como los acontecidos en el borde costero. Al parecer, únicamente el río Chol-Chol inundó poblados emergentes como Nueva Imperial y Chol-Chol a un nivel como para preocupar a las autoridades locales. En 1905 el gobernador del departamento de Imperial escribía en su memoria que era urgente construir obras de defensa a lo largo del río Chol-Chol, en Nueva Imperial, ya que cada vez se inundaba más el poblado producto de las crecidas del río. Según el Gobernador, la continua corta del bosque en el valle del Chol-Chol y el embancamiento de las aguas del río se hallaban detrás de este fenómeno ${ }^{120}$. En 1918 las inundaciones seguían ocurriendo en Nueva Imperial y ${ }^{121}$, en 1922, en Chol-Chol ${ }^{122}$. En todo caso, no se descarta que ríos como el Cautín y el Quepe, entre otros, también hayan generado problemas a los colonos. Los registros muestran algunos llamados, por parte de las autoridades locales, a reparar prontamente los puentes sobre dichos ríos que son ampliamente utilizados por los habitantes de Villa Almagro y de Boroa ${ }^{123}$. En Pitrufquén, a inicios del siglo XX, el río Toltén de igual modo parece haber inundado las partes más bajas del poblado ${ }^{124}$.

El clima no habría sido tan lluvioso como en el borde costero de la región y, por ende, no fue tan determinante en la colonización del departamento. No se puede olvidar que la cordillera de la costa impide, de cierto modo, la llegada de lluvias del oeste, otorgándole al clima local una condición de semicontinentalidad ${ }^{125}$. Todavía hoy se puede sentir una diferencia térmica entre el valle central y el litoral, existiendo por lo general temperaturas más estables y moderadas en la primera estructura morfológica que en la segunda. Las fuentes sugieren que

\footnotetext{
${ }^{118}$ Errázuriz, Isidoro. 2010. "Tres Razas”, p. 89.

${ }^{119}$ El relato de Isidoro Errázuriz, cuando recorre entre Chol-Chol y Temuco, da cuenta de numerosas quemas en el valle central. Errázuriz, Isidoro. 2010. "Tres Razas", pp. 42-85. El fotógrafo cholcholino Benedicto Rivas, tomó fotografías de los bosques chamuscados luego de las quemas. Véase Museo Regional de La Araucanía, Temuco, Exhibición temporal "Benedicto Rivas Núñez. Fotógrafo en La Frontera. Afectos y vida íntima en el registro fotográfico de Benedicto Rivas. Chol-Chol, 1915-1930", foto de Demetrio Rivas y Alfredo Kenner, Chol-Chol, 1925.

${ }^{120}$ ARA, Gobernación de Imperial, 30 de marzo de 1905, vol. 9, pp. 447-454.

${ }^{121}$ ARA, Gobernación de Imperial, 8 de noviembre de 1918, vol. 34, p. 13.

122 Museo Regional de La Araucanía, Temuco, Exhibición temporal "Benedicto Rivas Núñez. Fotógrafo en La Frontera. Afectos y vida íntima en el registro fotográfico de Benedicto Rivas. Chol-Chol, 1915-1930", 12 de julio de 1922, Chol-Chol.

${ }^{123}$ ARA, Gobernación de Imperial, vol. 30, p. 285; ARA, Gobernación de Imperial, 30 de marzo de 1905, vol. 9, pp. 447-454.

${ }^{124}$ Beissinger, Cerda, Mansilla, y Sepúlveda. 1999. Pitrufquén, p. 97.

125 Instituto Geográfico Militar. 1986. Geografía de Chile. IX región de La Araucanía, p. 67.
} 
las quejas de colonos o autoridades locales contra el clima fueron menores en número que las existentes en el borde costero.

En todo caso, la relativa facilidad con que se llevó a cabo la colonización de la depresión intermedia del departamento de Imperial no puede ser desligada de los instrumentos, dispositivos o tecnologías, aquí desplegados y dirigidos a agilizar las comunicaciones. El terreno no tan accidentado de esta estructura morfológica y el deseo del Gobierno central de unir prontamente La Araucanía con el resto del territorio nacional facilitaron el levantamiento de caminos y líneas férreas en este lugar del departamento. De hecho, las principales vías férreas y caminos de Chile cruzaron por este lugar como bien lo muestra un mapa caminero de $1904^{126}$. El tren ya había llegado en 1876 a Angol y, a Temuco y Pitrufquén lo hizo en 1895 y 1898, respectivamente. El objetivo del Gobierno era conectar a Chile ferroviariamente a lo largo del valle central para extraer los recursos naturales existentes en el territorio y fortalecer militarmente al país en caso de un enemigo interno y externo ${ }^{127}$. En este contexto, Pitrufquén y Nueva Imperial emergieron como verdaderos centros neurálgicos del comercio departamental y regional, al estar ubicados a orillas de los dos más importantes ríos locales, a saber: el Toltén y el Imperial. Pitrufquén servía de nodo para recibir-a través de balsas que bajaban por el río Toltén desde Villarrica-y enviar maderas nativas al resto de Chile por medio de la línea férrea ${ }^{128}$. Nueva Imperial cumplía un rol similar al estar a orillas de los ríos Imperial y Chol-Chol. Desde aquí se trasladaban, ya sea por tren o por barcos a vapor, maderas, cereales, papas y animales, entre otros productos, a lugares como Temuco, Traiguén y Puerto Saavedra ${ }^{129}$.

Es cierto que la tradición y modernidad identificada por el historiador Leonardo León seguían coexistiendo en La Araucanía durante el período aquí tratado ${ }^{130}$. Todavía se usaba el carruaje o la carreta, el caballo y la mula, para trasladarse de un punto a otro; todavía los colonos en Pitrufquén, Quepe, Radal y Faja Maisan, debían cruzar intrincados bosques y ríos para llegar a los diferentes poblados para acceder a servicios básicos ${ }^{131}$; y todavía en 1918, en Chol-Chol, los misioneros anglicanos debían cruzar a pie algunas secciones del río homónimo para misionar a través del campo ${ }^{132}$. Sin embargo, todo apunta a que la clase gobernante o más ilustrada de la época creía en el progreso, y la instalación de nuevos caminos y líneas férreas en

\footnotetext{
${ }^{126}$ AHN, Ministerio de Obras Públicas (ANHMOP), Mapa caminero de Chile, 1904, vol. 00853, p. 192.

127 Verniory. 2001. Diez años en La Araucanía, p. 97.

${ }^{128}$ Beissinger, Cerda, Mansilla, y Sepúlveda. 1999. Pitrufquén, p. 46

129 Flores, Jaime. 2013. "Economía y vías de transportes", pp. 60-75.

130 León, Leonardo. 2007. “Tradición y Modernidad: vida cotidiana en La Araucanía (1900-1935)”, en Historia, vol. II, Santiago, pp. 333-378.

${ }^{131}$ Biblioteca Municipal de Pitrufquén, Bélgica Velásquez, s/a, Faja Maisan, s/f.

132 Biblioteca Municipal de Chol-Chol, Fotografía de Misioneros anglicanos cargando a dos misioneras por el país, 1918, Chol-Chol.
} 
el valle central, constituían un ejemplo de lo mismo. En este contexto se deben entender las palabras de triunfo expresadas por el presidente José Manuel Balmaceda durante la inauguración del viaducto Malleco, en $1891^{133}$, y el poema escrito por Ana Vidal, estudiante de Nueva Imperial, en 1911, titulado Mi ideal acerca de Chile. En uno de sus pasajes dice: "En mis sueños he visto a mi patria avanzar por los campos del progreso, majestuosa, grande y respetada [...] Sus montes majestuosos los he visto horadados por el brazo musculoso de sus hijos [...] ¡Qué hermoso sueño! Millones de trenes cruzábanse en todas direcciones"134. Los colonos alemanes, provenientes de un país líder en el desarrollo industrial, debieron sentir algo similar ${ }^{135}$.

Después de todo, durante el avance de la línea férrea a lo largo del valle central se estrenaron, por primera vez en la provincia del Cautín y, más específicamente, en el departamento de Imperial, técnicas de la revolución industrial que hacía no mucho, los países más avanzados de Occidente habían inaugurado en sus tierras ${ }^{136}$. Fue en Quinquén, cerca de Quepe, en 1896, que se construyó un túnel ferroviario de 200 metros de longitud por medio del uso de dinamitas ${ }^{137}$, explosivos recién creados en 1867 por el suizo Alfred Nobel y que revolucionarían el arte de construir túneles ${ }^{138}$. Asimismo, fue con el puente ferroviario tendido sobre el río Toltén, de unos 450 metros de largo, que se usó la peligrosa-pero innovadora-técnica de cimentación con cajones de aire comprimidos ${ }^{139}$. Esta consistía en introducir a los obreros dentro de los postes que sostendrían al puente y descenderlos al nivel del lecho del río e, incluso más abajo, para que excavaran la profundidad necesaria para enterrar los pilares. Para que el agua no ingresara a donde se encontraban los obreros, se aumentaba, por medio de motores especializados, la presión atmosférica al interior del pilar. Esta era una técnica altamente riesgosa, porque quien trabajaba en la excavación se encontraba propenso a sufrir mareos, sordera e inclusive la muerte al exponer su cuerpo a los cambios de

\footnotetext{
133 "Este maravilloso monumento [dijo Balmaceda] marcará las jeneraciones venideras de la época en que los chilenos sacudieron su tradicional timidez i apatía i emprendieron la obra de un nuevo i sólido engrandecimiento". Marín, Santiago. 1901. Estudios de los ferrocarriles chilenos, Santiago, Imprenta Cervantes, p. 102.

${ }^{134}$ BN, Sección Periódicos, "Mi ideal acerca de Chile", El Ideal, Nueva Imperial, 7 de diciembre de 1911, p. 2.

${ }^{135} \mathrm{El}$ colono alemán e industrial, Carlos Anwandter, habría dicho ante la comisión chilena encargada de establecerlo a él y su familia en Valdivia que: "Seremos chilenos honrados y laboriosos como el que más lo fuere. Unidos a las filas de nuestros nuevos compatriotas, defenderemos nuestro país adoptivo contra toda agresión extranjera con la decisión y la firmeza del hombre que defiende a su patria, a su familia y a sus intereses". Pérez R., Vicente. 2007. Recuerdos del pasado, Santiago, Dulce Patria, p. 412

136 Las técnicas que se describirán ya venían siendo ocupadas en Chile a través de la construcción del ramal Valparaíso-Santiago (1853-1862) y en la instalación del puente ferroviario sobre el río Biobío, inaugurado en 1890.

137 Verniory. 2001. Diez años en La Araucanía, p. 424.

${ }^{138}$ Meyers, Sydney; y Edward Shanley. 1990. "Industrial explosives-a brief history of their development and use", en Journal of Hazardous Materials, 23, Amsterdam, pp. 183-201.

${ }^{139}$ Verniory. 2001. Diez años en La Araucanía, pp. 454-484.
} 
presión. Sin embargo, era una técnica que desde 1851 venía permitiendo el levantamiento de puentes en las principales potencias industriales de la época ${ }^{140}$.

Por lo tanto, la colonización del valle central no solo se estaba viendo facilitada por un medio ambiente menos hostil o más fácil de enfrentar, sino también por un despliegue material que aseguraba-o al menos sugería-cierto control humano sobre la naturaleza ${ }^{141}$.

La capacidad de adaptación de los colonos al medio ambiente también es un elemento que debe ser considerado en esta discusión. Como bien lo ha advertido el historiador Marco Armiero, no se puede tratar a los inmigrantes o colonos como un grupo coherente o unitario, sino que como un conjunto de personas con diferencias de clase, género y etnia ${ }^{142}$. En este sentido, el que los colonos europeos asentados en el valle central hayan provenido mayoritariamente de Alemania, Suiza, Bélgica y Francia, debió de significar una ventaja sobre los inmigrantes provenientes de países más cálidos como España e Italia ${ }^{143}$, pues se encontraban más acostumbrados al clima lluvioso ${ }^{144}$. En el caso de los chilenos, las fuentes sugieren que estaban más o menos preparados para coexistir con un territorio como el de La Araucanía ${ }^{145}$.

Otro factor que debió facilitar el asentamiento de colonos en el valle central debió ser la presencia indígena. Se ha mencionado que el éxito o el fracaso de una inmigración, dependerá, en parte, de la sociedad que reciba al inmigrante ${ }^{146}$. Las posibilidades de adaptación de este último se verán incrementadas si, por ejemplo, la sociedad o país receptor posee instituciones capacitadas para gestionar la estancia del nuevo poblador. Las fuentes sugieren que en la depresión intermedia la sociedad receptora además de estar representada por las empresas de colonización o el Estado que, con sus agentes, se encargaban de instalar a los colonos en las distintas tierras de la región, también lo estuvo por los mapuche. En efecto, se podría decir que estos facilitaron el proceso colonizador al ayudar a los colonos a no pasar tantas penurias

\footnotetext{
140 Yepes, Víctor. 2016. Cimentación mediante cajones de aire comprimido. Disponible en: https://victoryepes.blogs.upv.es/ [fecha de consulta: 26 de diciembre de 2019].

${ }^{141}$ De acuerdo al historiador británico Eric Hobsbawm, los avances técnicos y científicos de la segunda mitad del siglo XIX le estaban dando al ser humano occidental la sensación de que no solo estaba entendiendo el funcionamiento de la naturaleza, sino que también la posibilidad de controlarla. Hobsbawm, Eric. 2007. La Era del Capital, pp. 202217.

142 Armiero, Marco. 2017. "Migrants and the making of the American landscape", en Environmental History of Modern Migrations, Armiero, Marco; y Richard Tucker (editores), London, Routledge, p. 55.

${ }^{143}$ Ya se vio lo que sucedió con los inmigrantes españoles en las riberas del lago Budi. Los italianos pasaron grandes penurias cuando llegaron a habitar el valle en que sería fundado Capitán Pastene, en la provincia de Malleco. Véase Contreras, Juan; y Gino Venturelli. 1988. Nueva Italia. Un ensayo de colonización italiana en la Araucanía, 1903-1906, Temuco, Ediciones Universidad de La Frontera, pp. 67-94.

${ }^{144}$ Ya en Puerto Montt, que es más lluvioso que La Araucanía, el colono alemán Konrad Epple daba a entender en una carta dirigida a su padre, en 1853, que el clima no era muy distinto al de su tierra natal. Revista Sescoal. 1996. 150 años de colonización alemana, Puerto Montt, Imprenta regional, pp. 46-47.

${ }^{145}$ ARA, Gobernación de Imperial, 1904, vol. 33, pp. 353-367.

${ }^{146}$ Harzig, Christiane; y Dirk Hoerder. 2009. What is Migration History? Cambridge, Polity Press, pp. 102-110.
} 
entregándoles alimentos y posiblemente enseñándoles los mejores sitios para asentarse. Al fin y al cabo, los mapuche conocían mejor que nadie la geografía del departamento de Imperial, al ser ellos los más antiguos habitantes del territorio. Errázuriz vio a colonos chilenos conviviendo con mapuches en los campos de estos, entre Nueva Imperial y Labranza ${ }^{147}$. En Faja Maisan los mapuche proporcionaron suministros a los alemanes que llegaron a instalarse al lugar, a inicios del siglo $X X^{148}$. En las cercanías de Quepe, en 1892, mapuches y colonos se unieron para combatir a la plaga de langostas que, llegada de Argentina, estaba devastando sus cultivos ${ }^{149}$. Inclusive en el mismo lago Budi, los mapuche se unieron, en ocasiones, a los colonos chilenos y europeos que protestaban ante las autoridades locales por un mejor reparto de las tierras ${ }^{150}$. Es verdad que hubo numerosos episodios de conflicto entre colonos e indígenas, especialmente en torno al deslinde de las propiedade ${ }^{151}$; sin embargo, esa no fue la única realidad existente, porque, como aquí se ha demostrado, también hubo interacciones que podrían ser calificadas de amistosas. En cualquier caso, todo parece indicar que los abusos cometidos en contra del mapuche provinieron más de colonos chilenos que de extranjeros ${ }^{152}$.

Cabe destacar un hecho ambiental que dejó en evidencia la vulnerabilidad de la depresión intermedia y sus colonos a la naturaleza. En una historia aparentemente marcada por el triunfo sobre el medio o de avance contra el mismo, ocurrió un evento que demostró lo contrario, aun cuando haya ocurrido en un espacio de tiempo acotado. Curiosamente, fue un evento externo a las particularidades geográficas del territorio hasta aquí comentadas, a saber: una plaga de langostas provenientes de Argentina. En diciembre de 1891, un gran número de langostas (Schistocerca cancellata) ingresaron al departamento luego de haber cruzado la cordillera de los Andes por San Junín de Los Andes y Pucón ${ }^{153}$. Si bien, las plagas de langostas no habían sido nuevas en la región - pues hubo misioneros que afirmaron haberlas visto en otras ocasiones-, lo que sí era inédito era que se trataba de langostas "argentinas" ${ }^{154}$. De acuerdo al entomólogo

\footnotetext{
${ }^{147}$ Errázuriz, Isidoro. 2010. "Tres Razas”, p. 77.

148 Biblioteca Municipal de Pitrufquén, Bélgica Velásquez, s/a, Faja Maisan, s/f.

${ }^{149}$ ANHMOP Antecedentes-Langostas, 17 de diciembre, 1891, vol. 00587, s/f.

${ }^{150}$ ARA, Gobernación de Imperial, vol. 9, 28 de octubre, 1904.

151 ARA, Gobernación de Imperial, Nueva Imperial, 1904, vol. 50, f.129; ARA, Gobernación de Imperial, Nueva Imperial, 1914, vol. 27, p. 231.

${ }^{152}$ Isidoro Errázuriz escribió en su diario de viaje: "Es muy escaso el número de los delitos que cometen los indígenas, y aun en los casos en que se les cree culpables, habría que averiguar si, en el fondo, no anda por ahí la mano del huinca [sic] malo". Errázuriz, Isidoro. 2010. "Tres Razas", p. 61. Errázuriz es duro en su crítica hacia el chileno. Para Errázuriz, ha sido él quien ha sembrado, en gran medida, el desorden entre los mapuche. "El chileno se convirtió en entrometido, altanero, ocioso, bebedor y tirano". Además, el número de chilenos instalados ilegalmente en propiedades indígenas iba en aumento, según el ministro. Ibíd., pp. 62-63. Para mayor detalle de esta situación en la frontera, véase: León, Leonardo. 2005. Araucanía: la violencia mestiza y el mito de la pacificación, 1880-1900, Santiago, Editorial ARCIS, passim.

${ }^{153}$ ANHMOP, Antecedentes-Langostas, 17 de diciembre, 1891, vol. 00587, s/f.

${ }^{154}$ ANHMOP, Antecedentes-Langostas, comunicado telegráfico, vol. 00587, 15 de diciembre, 1891, Valdivia, p. 3.
} 
Edwyn Reed: "Si es la terrible especie argentina que ha invadido a Chile es menester tomar medidas enérgicas y sin pérdida de tiempo, pero si es, como espero, solamente una sobreabundancia de las especies comunes del país, entonces no hay razón de alarmarse ni hacer grandes gastos"155. El fuerte viento reinante, la baja altitud cordillerana en esta zona de la región y las altas temperaturas de la temporada se conjugaron para facilitar la llegada del insecto trasandino. Las autoridades locales y nacionales vieron con especial preocupación este hecho, porque sabían que los cultivos de papas, de maíz, de cebada y especialmente de trigo, se verían afectados por este hecho, dejando en hambruna a gran parte de la población regional. Si bien, el daño ocasionado por las langostas no fue tan grave como el esperado, sí se verificaron hechos de destrucción agrícola, especialmente en torno a Villarrica, donde los indígenas fueron los principales afectados ${ }^{156}$. Según los especialistas destinados a enfrentar la situación, la langosta prefería asentarse en zonas cálidas y de bajas precipitaciones, y de aquí que las nubes de langostas se hayan dirigido progresivamente hacia el Norte, hacia la provincia de Malleco, región del Bío-Bío e inclusive hacia ciudades tan lejanas como Cauquenes ${ }^{157}$. Se descubrió, con el tiempo, que las provincias del Cautín y de Valdivia eran demasiado boscosas y lluviosas como para alojar permanentemente a las langostas. Hubo "mangas de langosta" que se estacionaron en el departamento de Imperial, tanto en Toltén como a lo largo del valle central. Según los informes, el insecto se acumuló preferentemente en torno a Pitrufquén y Quepecoincidentemente las zonas más agrícolas y habitadas por indígenas y colonos-, conformando una capa de diez leguas de largo por seis de ancho ${ }^{158}$. De las fuentes se desprende el profundo temor que ocasionó la invasión del acrídido, al amenazar la estabilidad social y económica del territorio afectado. Se hablaba de hambrunas, pérdidas económicas irrecuperables y hasta de trenes detenidos-uno de los principales símbolos del progreso de la época- ${ }^{159}$. El fuego y los recursos humanos empleados para su destrucción parecían no ser suficientes. No obstante, hacia finales de 1892, la plaga ya parecía estar controlada.

La experiencia de las langostas es interesante porque refleja cómo el medio ambiente podía generar estragos en una sociedad que crecientemente confiaba más en el progreso y en su capacidad de controlar a la naturaleza. De hecho, la langosta se vio atraída por el principal rubro económico de la región y por una de las principales causas por la cual se despejó al bosque-la

\footnotetext{
155 ANHMOP, Antecedentes-Langostas, 17 de diciembre, 1891, vol. 00587, s/f.

156 Ídem

${ }^{157}$ ANHMOP , Antecedentes-Langostas, 3 de septiembre, 1892, vol. 00587, s/f.

${ }_{158}$ ANHMOP, Antecedentes-Langostas, 17 de diciembre, 1891, vol. 00587, s/f.

${ }^{159}$ En Mininco, el tren no habría podido continuar su viaje por espesas masas de langostas que aterrizaron sobre los rieles ANHMOP, Antecedentes-Langostas, 3 de septiembre, 1892, vol. 00587, s/f.
} 
agricultura-. Paradójicamente, el relativo triunfo del ser humano sobre la naturaleza del valle central, lo había dejado vulnerable a otros eventos provenientes del mismo medio ambiente ${ }^{160}$.

En síntesis, los bosques, el clima y los ríos del valle central no se impusieron a los colonos de la misma forma que en el borde costero. Hubo tecnología de transporte que facilitó este proceso; y los colonos que llegaron parecían estar más preparados para enfrentar un medio ambiente como el del departamento de Imperial.

\section{Conclusiones}

En el departamento de Imperial la inmigración se vio afectada por el medio ambiente de diferente forma, entre 1866 y 1920. En el borde costero el medio ambiente, en general, se impuso; mientras que en el valle central, el ser humano se logró adaptar de manera más exitosa al entorno natural. Las montañas boscosas del borde costero obligaron a que los asentamientos se concentraran en zonas bajas. Esto provocó que los colonos fueran más vulnerables a aluviones invernales provenientes de los ríos Toltén e Imperial. Aquí, la combinación de inviernos lluviosos con tierras bajas y anegadizas, y con cauces de ríos que se sedimentaban producto de la creciente tala de árboles en las cuencas-siendo, al parecer, la cuenca del río Imperial la más afectada en este sentido-generó el contexto propicio para que se desarrollaran inundaciones inusuales y destructivas. En todo caso, los suelos despejados eran escasos en número. La mayoría lo poseían los mapuche y, los que no, estaban cubiertos de bosque. El Estado chileno también encontró problemas para hacerse presente en el lugar, pues la envergadura del territorio y la escasez de funcionarios atentaron con su interés de administrar apropiadamente al borde costero. Esto contribuyó al despliegue de la delincuencia, al continuo problema de deslindes de propiedades entre colonos-especialmente chilenos-e indígenas y a la explotación desregulada de los bosques. Una historia un tanto distinta se vio en el valle central del departamento. Si bien, aquí el Estado también tuvo problemas para ejercer soberanía, los resultados muestran que, en general, el medio ambiente no se impuso con la misma intensidad al establecimiento de los colonos. Las lluvias intensas, el desborde de ríos y la omnipresencia del bosque no habrían sido rasgos tan presentes como en el litoral del territorio. Además, el proceso colonizador se habría visto reforzado por el arribo de técnicas o tecnologías industriales que, para la época, le estaban otorgando al ser humano una mayor capacidad de maniobra ante las constricciones que podía generar la geografía de un determinado lugar. El origen de los colonos también habría sido un factor contribuyente a este relativo éxito colonizador. La mayoría de los colonos extranjeros provenían de naciones europeas con climas similares a los de La Araucanía. No obstante, el aparente progreso

\footnotetext{
${ }^{160}$ El entomólogo Edwyn Reed, escribía el 3 de septiembre de 1892, que donde había campos cultivados, la langosta indígena estaba causando estragos. AHN, Ministerio de Obras Públicas, Antecedentes-Langostas, 3 de septiembre, 1892, vol. 00587, s/f.
} 
colonizador del valle central fue puesto en jaque, aunque por un breve período, por una plaga de langostas provenientes de Argentina.

Con el siguiente estudio no se pretende instalar al medio ambiente como factor determinante en la inmigración de colonos, al menos para el antiguo departamento de Imperial, en la región de La Araucanía; sino que, lo que se intenta, es integrar en la explicación de este proceso, un actor por lo general olvidado en las historias de las migraciones, el medio ambiente natural. La experiencia del departamento de Imperial en torno a la colonización podría servir de insumo para una mejor gestión de los procesos migratorios que actualmente afectan a Chile. Además, podría servir de recordatorio de que la naturaleza puede alterar significativamente la vida de las personas, aun cuando estas vivan confiadas en el bienestar otorgado por el progreso material y económico.

Hubo aspectos de la migración que, en esta ocasión, pudieron haber sido más profundizados. Se puede ahondar aún más, por ejemplo, en la sociedad de origen de los inmigrantes, en las condiciones de viaje que imperaban en la época y en la función que ejercieron los mapuche en la recepción de los inmigrantes. Se podría entrar en mayor detalle en las diferencias culturales que cada nación migrante poseía al momento de su llegada a la región. De hecho, quizás hubo diferencias de género en cuanto a la adaptabilidad ambiental. Solo así se podrá ir realizando una historia más completa o representativa de las migraciones en el sur de Chile. Las oportunidades de estudiar las migraciones en La Araucanía son riquísimas, sobre todo desde el ámbito de la historia ambiental.

\section{Fuentes y Bibliografía}

\section{Fuentes}

Archivo Regional de La Araucanía (ARA), Temuco-Chile, Gobernación de Imperial: vols., 9, 24, 27, 29, 30 , $31,33,34,43,50,51,53,54,62,64$.

ARA, Temuco-Chile, Gobernación de Toltén: vol. 1.

ARA, Temuco-Chile, Memorias Ministeriales: vol. 1.

Archivo Histórico Nacional (AHN), Santiago-Chile, Intendencia de Valdivia: vols., 30, 92, 129, 195, 229.

AHN, Santiago-Chile, Gobernación de Villarrica: vol. 237.

AHN, Santiago-Chile, Ministerio de Obras Públicas: vols., 00587, 00853.

Biblioteca Nacional de Chile (BN), Santiago-Chile, Sección Periódicos: El Diario Austral, "El Budi i Colonos nacionales", 29 de mayo de 1917, p. 4; "Mi ideal acerca de Chile", El Ideal, Nueva Imperial, 7 de diciembre de 1911, p. 2.

BN, Santiago-Chile, Sala Medina: AD. № 10923.

Biblioteca Municipal de Pitrufquén, Bélgica Velásquez, s/a, Faja Maisan, s/f.

Biblioteca Municipal de Chol-Chol, Fotografía de Misioneros anglicanos cargando a dos misioneras por el país, 1918.

Museo Regional de La Araucanía, Temuco, Exhibición temporal "Benedicto Rivas Núñez. Fotógrafo en La Frontera. Afectos y vida íntima en el registro fotográfico de Benedicto Rivas. Chol-Chol, 1915-1930". 


\section{Bibliografía}

Armiero, Marco. 2017. "Migrants and the making of the American landscape", en Armiero, Marco y Richard Tucker (eds.), Environmental History of Modern Migrations, London, Routledge, pp. 53-71.

Aninat, Isabel y Rodrigo Vergara. 2019. Inmigración en Chile. Una Mirada multidimensional, Santiago, Fondo de Cultura Económica.

Aldunate, Carlos. 1997. "En el país de los lagos, bosques y volcanes", en Chile antes de Chile, prehistoria, Santiago, Museo Chileno de Arte Precolombino.

Bartram, Rob. 2010. "Geography and the Interpretation of Visual Imagery", en Clifford, Nicholas, French, Shaun y Gill, Valentine (eds.), Key Methods in Geography, Los Angeles, Sage publications, pp. 131140.

Beissinger, Frantz, Cerda, Eduardo, Mansilla, Juan, y Ramsés Sepúlveda. 1999. Pitrufquén: Entre la historia y la memoria, Pitrufquén, Ilustre Municipalidad de Pitrufquén.

Bengoa, José. 2008. Historia del pueblo mapuche: siglos XIX y XX, Santiago, Lom ediciones.

Camus G., Pablo. 2006. Ambiente, Bosques y Gestión Forestal en Chile. 1541-2005, Santiago, LOM ediciones.

Camus, Pablo y Solari, María. 2008. "La invención de la selva austral. Bosques y tierras despejadas en la cuenca del río Valdivia (siglos XVI-XIX)", en Revista de Geografía Norte Grande, vol. 40, Santiago, pp. 5-22.

Cisternas, Marco, Atwater, Brian F., Torrejón, Fernando, Sawai, Yuki, Machuca, Gonzalo, Lagos, Marcelo, Eipert, Annaliese, Youlton, Cristián, Salgado, Ignacio, Kamataki, Takanobu, Shishikura, Masanobu, Rajendran, C. P., Malik, Javed K., Rizal, Yan, Husni, Muhammad. 2005. "Predecessors of the giant 1960 Chile earthquake", en Nature, vol. 437, London, pp. 404-407.

Chaigneau, Federico. 1896. "Viaje al río Imperial en noviembre de 1893 por el capitán de fragata Don J. Federico Chaigneau", en Anuario Hidrográfico de la Marina de Chile, 20, Santiago, pp. 43-58.

Cunill, Pedro. 1999. "La Geohistoria”, en Carmagnani, Marcello, Hernández, Alicia, y Romano Ruggiero (eds.), Para una historia de América. I. Las estructuras, México, Fondo de Cultura Económica, pp. 13159.

Chester, Sharon. 2016. Flora y Fauna de Chile. Guía de Identificación, Barcelona, Lynx

Clifford, Nick, French, Shaun, y Gill Valentine. 2010. "Getting Started in Geographical Research: how this book can help", en Clifford, Nicholas, French, Shaun y Gill Valentine (eds.), Key Methods in Geography, Los Angeles, Sage publications, pp. 3-16.

Contreras, Juan y Gino Venturelli. 1988. Nueva Italia. Un ensayo de colonización italiana en la Araucanía, 1903-1906, Temuco, Ediciones Universidad de La Frontera

Domeyko, Ignacio. 2010. La Araucanía y sus habitantes, Santiago, Biblioteca Fundamentos de la Construcción de Chile.

Dirección General de Estadística. 1931. Resultados del X censo de la población efectuado el 27 de noviembre de 1930 y estadísticas comparativas con otros censos anteriores, Santiago, Imprenta Universo.

Errázuriz, Isidoro. 2010. "Tres Razas", en Revista Andes del Sur, 2, Temuco, pp. 1-152.

Espinoza, Eduardo. 1897. Geografía descriptiva de la República de Chile, Santiago de Chile, Imprenta Barcelona.

Ferrando, Ricardo. 2012. Y así nació La Frontera...Conquista, guerra, ocupación, pacificación, 1550-1900, Temuco, Universidad Católica de Temuco. 
Flores, Jaime. 2013. "Economía y vías de transportes. La construcción del espacio regional, La Araucanía 1880-1940", en Carlos Zúñiga (comp.), Fragmentos de Historia Regional. La Araucanía en el siglo XX, Temuco, ediciones Universidad de la Frontera, pp. 60-75.

González, Matías. 2020. "Civilizing Nature with the Spade and the Rifle: The Engineer Battalion in the Araucanía Region, Chile (1877-1891)", en Arcadia (Spring 2020), no 21, Rachel Carson Center for Environment and Society. Disponible en: Environment \& Society Portal Disponible en: http://www.environmentandsociety.org/node/9043. (consultado el 29 de octubre de 2020).

González M., Matías y Torrejón G., Fernando. 2020. “Para construir, comerciar y ¿proteger? La explotación del bosque caducifolio del llano en el antiguo departamento de Imperial (región de La Araucanía), 1867-1920", en Historia, n53, vol. II, Santiago, (en prensa).

Gallini, Stefania. 2009. "Historia, ambienta, política: el camino de la historia ambiental en América Latina”, en Nómadas, no 30, Bogotá, pp. 92-102.

Harzig, Christiane y Dirk Hoerder. 2009. What is Migration History?, Cambridge, Polity Press.

Hobsbawm, Eric. 2007. La Era del Capital, 1848-1875, Barcelona, Editorial Crítica.

Hobsbawm, Eric. 2007. La Era del Imperio, 1875-1914, Barcelona, Editorial Crítica.

Hughes. 2016. What is Environmental History?, Cambridge, Polity Press.

Instituto Geográfico Militar. 1986. Geografía de Chile. IX región de La Araucanía, Santiago, Instituto Geográfico Militar.

Instituto Geográfico Militar. 1986. Biogeografía, Santiago, Instituto Geográfico Militar.

Klug, João. 2017. “Da Aelamanha para a floresta subtropical brasileira: as propostas do Dr. Paul Aldinger para as colônias alemãs no sul do Brasil", en Gerhardt, Marcos, Nodari, Eunice Sueli y Moretto, Samira Peruchi (orgs.), História e Migrações. Diálogos, São Leopoldo, Oikos editora, pp. 45-62.

Kenny, Judith. 1995. "Race, and Imperial Authority: The Symbolic Landscape of the British Hill Station in India", en Annals of the Association of American Geographers, no 4, vol. 85, Cambridge, pp. 694-714.

Leal, Claudia. 2019. "Selvas: amenazantes y amenazadas", en Leal, Claudia, Soluri, John y Pádua, José Augusto (eds.), Un pasado vivo. Dos siglos de historia ambiental latinoamericana, México D.F., Fondo de Cultura Económica, pp. 127-149.

Livingstone, David. 1999. "Tropical climate and moral hygiene: the anatomy of a Victorian debate", en The British Journal for the History of Science, n1, vol. 32, Cambridge, pp. 93-110.

Livi, Massimo. 2012. Breve historia de las migraciones, Madrid, Alianza Editorial.

León, Leonardo. 2007. "Tradición y Modernidad: vida cotidiana en La Araucanía (1900-1935)", en Historia, Vol. II, Santiago, pp. 333-378.

León, Leonardo. 2005. Araucanía: la violencia mestiza y el mito de la pacificación, 1880-1900, Santiago, Editorial ARCIS.

Marín, Santiago. 1901. Estudios de los ferrocarriles chilenos, Santiago de Chile, Imprenta Cervantes.

Mardones, Marco. 2005. "La Cordillera de la Costa: caracterización físico-ambiental y regiones", en Smith-Ramírez, Cecilia, Armesto, Juan y Valdovinos, Claudio (eds.), Historia, biodiversidad y ecología de los bosques costeros de Chile, Santiago de Chile, Editorial Universitaria, pp. 39-78.

Merello, Ítalo. 1988. Historia del derecho, Valparaíso, Ediciones Universidad Católica de Valparaíso.

Meyers, Sydney y Edward Shanley. 1990. "Industrial explosives-a brief history of their development and use", en Journal of Hazardous Materials, 23, Amsterdam, pp. 183-201.

Miller K., Thomas. 2014. La Frontera. Forests and Ecological Conflict in Chile's Frontier Territory, Durham, Duke University Press.

McNeill, John. 2005. "Naturaleza y cultura de la historia ambiental”, en Nómadas (Colombia), no 22, Bogotá, pp. 12-25.

Navarro, Leandro. 2008. Crónica militar de la conquista y pacificación de la Araucanía, desde el año 1859 hasta su completa incorporación al territorio nacional, Santiago, Pehuén editores. 
Otero D., Luis. 2006. La huella del fuego. Historia de los bosques nativos. Poblamiento y cambios en el paisaje del sur de Chile, Santiago, Pehuén editores.

Pratt, Mary. 2010. Ojos imperiales. Literatura de viajes y transculturación, México D.F., Fondo de Cultura Económica.

Pinto, Jorge. 2000. La formación del Estado y la nación y el pueblo mapuche. De la inclusión a la exclusión, Santiago, Ediciones de la Dirección de Bibliotecas, Archivos y Museos.

Pinto, Jorge. 2011. Araucanía, siglos XIX y XX, Economía, Migraciones y Marginalidad, Ediciones Universidad de la Frontera, Temuco.

Pérez R., Vicente. 2007. Recuerdos del pasado, Santiago, Dulce Patria.

Revista Sescoal. 1996. 150 años de colonización alemana, Puerto Montt, Imprenta regional.

Rojas, Nicolás y Vicuña, José. 2019. Migración en Chile. Evidencia y mitos de una nueva realidad, Santiago, LOM editores.

Soluri, John, Leal, Claudia, Pádua, José. 2019. “Introducción. Lo 'latinoamericano’ en la historia ambiental de América Latina”, en Leal, Claudia, Soluri, John, Pádua, José (eds.), Un pasado vivo. Dos siglos de historia ambiental latinoamericana, México D.F., Fondo de Cultura Económica, pp. 11-32.

Stewart, Daniel. 2019. "Historical tsunamis in the Concepcion bay, as seen in the reconstructed flood levels from the colonial city of Concepcion (Penco), Chile (1570-1835)", en Revista de Historia, no26, vol. 2, Concepción, pp. 97-127.

Smith, Edmund. 1914. Los Araucanos. Notas sobre una gira efectuada entre las tribus indígenas de Chile Meridional. Santiago, Imprenta Universitaria.

Smith, Edmund. 2016. "Los araucanos. Notas sobre una gira efectuada entre las tribus indígenas de Chile meridional”, en Salgado, Ítalo (comp.), Travesías por La Araucanía: relatos de viajeros de mediados del siglo XIX, Temuco, Ediciones Universidad Católica de Temuco, pp. 123-243.

Saavedra, Cornelio. 2009. Documentos relativos a la ocupación de Arauco, Santiago de Chile, Biblioteca Fundamentos de la Construcción de Chile.

Schmutzer S., Karin. 1981. “Aventuras de un inglés en Chile. Guillermo Watkins, 1838-1880”, en Historia, no16, vol. I, Santiago, pp. 67-124.

Tijoux, María E. 2016. Racismo en Chile. La piel como marca de la inmigración, Santiago, Editorial Universitaria.

Varios autores. 2014. Voces Ancestrales. Cuentos de Quepe, Freire, RENDCL Impresiones.

Villalobos, Sergio. 2013. Incorporación de La Araucanía. Relatos Militares, 1822-1883, Santiago, Catalonia.

Verniory, Gustav. 2001. Diez años en La Araucanía, 1889-1899, Santiago, Pehuén editores.

Villalba, Álvaro. 2013. "Conflicto político y social en la Araucanía a principios del siglo XX, en el proceso de colonización extranjera con españoles canarios en la zona del Budi", en Carlos Zúñiga (comp.), Fragmentos de Historia Regional. La Araucanía en el siglo XX, Temuco, ediciones Universidad de la Frontera, pp. 122-157.

Worster, Donald. 1988. "Appendix: Doing Environmental History”, en Worster, Donald (ed.), The Ends of the Earth. Perspectives on modern environmental history, Cambridge, Cambridge University Press, pp. 289-307.

Yepes, Víctor. 2016. Cimentación mediante cajones de aire comprimido. Disponible en: https://victoryepes.blogs.upv.es/ (Consultado el 26 de diciembre de 2019).

Zavala, José. 2018. "En busca del ciudadano ideal: fundamentos discursivos de la colonización inmigratoria de La Araucanía durante el siglo XIX", en Mora, Héctor y Mario Samaniego (eds.), EI pueblo mapuche en la pluma de los araucanistas. Seis estudios sobre construcción de la alteridad, Santiago de Chile, Ocholibros, pp. 167-185. 
Zúñiga, Carlos. 2013. “La explotación del bosque nativo en la zona de Villarrica. Una aproximación desde la historia oral”, en Zúñiga, Carlos (comp.), Fragmentos de Historia Regional. La Araucanía en el siglo $X X$, Temuco, ediciones Universidad de la Frontera, pp. 160-200. 